\title{
Cloud droplet size and liquid water path retrievals from zenith radiance measurements: examples from the Atmospheric Radiation Measurement Program and the Aerosol Robotic Network
}

\author{
J. C. Chiu ${ }^{1}$, A. Marshak ${ }^{2}$, C.-H. Huang ${ }^{2,3}$, T. Várnai ${ }^{2,4}$, R. J. Hogan ${ }^{1}$, D. M. Giles ${ }^{5}$, B. N. Holben ${ }^{2}$, E. J. O'Connor ${ }^{1,6}$, \\ Y. Knyazikhin ${ }^{7}$, and W. J. Wiscombe ${ }^{2}$ \\ ${ }^{1}$ University of Reading, Reading, UK \\ ${ }^{2}$ NASA Goddard Space Flight Center, Greenbelt, MD, USA \\ ${ }^{3}$ Science Systems and Applications, Inc., Lanham, MD, USA \\ ${ }^{4}$ University of Maryland - Baltimore County, Baltimore, MD, USA \\ ${ }^{5}$ Sigma Space Corporation, Lanham, MD, USA \\ ${ }^{6}$ Finnish Meteorological Institute, Helsinki, Finland \\ ${ }^{7}$ Boston University, Boston, MA, USA \\ Correspondence to: J. C. Chiu (c.j.chiu@reading.ac.uk)
}

Received: 10 July 2012 - Published in Atmos. Chem. Phys. Discuss.: 2 August 2012

Revised: 24 October 2012 - Accepted: 25 October 2012 - Published: 6 November 2012

\begin{abstract}
The ground-based Atmospheric Radiation Measurement Program (ARM) and NASA Aerosol Robotic Network (AERONET) routinely monitor clouds using zenith radiances at visible and near-infrared wavelengths. Using the transmittance calculated from such measurements, we have developed a new retrieval method for cloud effective droplet size and conducted extensive tests for non-precipitating liquid water clouds. The underlying principle is to combine a liquid-water-absorbing wavelength (i.e., $1640 \mathrm{~nm}$ ) with a non-water-absorbing wavelength for acquiring information on cloud droplet size and optical depth. For simulated stratocumulus clouds with liquid water path less than $300 \mathrm{~g} \mathrm{~m}^{-2}$ and horizontal resolution of $201 \mathrm{~m}$, the retrieval method underestimates the mean effective radius by $0.8 \mu \mathrm{m}$, with a root-mean-squared error of $1.7 \mu \mathrm{m}$ and a relative deviation of $13 \%$. For actual observations with a liquid water path less than $450 \mathrm{~g} \mathrm{~m}^{-2}$ at the ARM Oklahoma site during 20072008, our 1.5-min-averaged retrievals are generally larger by around $1 \mu \mathrm{m}$ than those from combined ground-based cloud radar and microwave radiometer at a 5-min temporal resolution. We also compared our retrievals to those from combined shortwave flux and microwave observations for relatively homogeneous clouds, showing that the bias between these two retrieval sets is negligible, but the error of $2.6 \mu \mathrm{m}$
\end{abstract}

and the relative deviation of $22 \%$ are larger than those found in our simulation case. Finally, the transmittance-based cloud effective droplet radii agree to better than $11 \%$ with satellite observations and have a negative bias of $1 \mu \mathrm{m}$. Overall, the retrieval method provides reasonable cloud effective radius estimates, which can enhance the cloud products of both ARM and AERONET.

\section{Introduction}

Cloud droplet effective radius is one of the most fundamental cloud properties for understanding cloud formation, dissipation and interactions with aerosol and drizzle (Albrecht, 1989; Wood, 2000; McComiskey at al, 2009; Kubar et al., 2009). Cloud droplet size is also a crucial determinant of cloud feedback processes, and of the Earth's radiative and water energy balance (Slingo, 1990; Wielicki et al., 1995; Stephens, 1999; Stephens et al., 2005). While tremendous efforts have been made in providing routine cloud droplet effective radii from satellite passive and active measurements (Nakajima and King, 1990; Han et al., 1994; Kawamoto et al., 2001; Chang and Li, 2002; Platnick et al., 2003; Roebeling et al., 2006; Mace et al., 2009; Minnis et al., 2011;

Published by Copernicus Publications on behalf of the European Geosciences Union. 
and many others), ground-based retrievals are limited and the discrepancies among different retrievals remain unresolved (Feingold et al., 2006; Schofield et al., 2007; Zhao et al., 2012).

Ground-based retrievals of cloud droplet size for liquid clouds are available from the Atmospheric Radiation Measurement (ARM) program in Oklahoma, Alaska, and the tropical western Pacific sites (Stokes and Schwartz, 1994). Some retrieval methods heavily rely on cloud radar and microwave radiometer measurements (Liao and Sassen, 1994; Frisch et al., 1995; 1998; Dong et al., 1998; Dong and Mace, 2003; Wang and Sassen, 2002; Wang et al., 2004), while others utilize a synergy of passive radiation measurements. Turner (2007) combined infrared and microwave radiometer measurements to retrieve cloud droplet radii; their method is limited to cases with liquid water paths less than $60 \mathrm{~g} \mathrm{~m}^{-2}$ due to saturation of the infrared observations. Min et al. (2003) used a least-squared error minimization technique to simultaneously retrieve cloud optical depth and effective radius using shortwave flux and microwave observations. Similarly, Feingold et al. (2006) and Kim et al. (2003) estimated cloud droplet radius using liquid water path derived from microwave radiometer and cloud optical depth from shortwave flux measurements.

A number of studies proposed to retrieve cloud droplet size using zenith radiance measurements at visible and nearinfrared wavelengths from single instruments (Kikuchi et al., 2006; Schofield et al., 2007; Pandithurai et al., 2009; McBride et al., 2011). The underlying principle for these transmittance-based methods is to combine a liquid-waterabsorbing wavelength with a non-water-absorbing wavelength to acquire information on cloud droplet size and optical depth. Kikuchi et al. (2006) and Pandithurai et al. (2009) used zenith radiance measurements at 1020, 1600 and $2200 \mathrm{~nm}$ wavelengths to simultaneously retrieve cloud optical depth and effective radius with a 1-min temporal resolution. For water clouds with effective radii ranging between 1-6 $\mu \mathrm{m}$, the retrieved cloud droplet radii from zenith radiance data were generally larger than those retrieved from cloud radar in Kikuchi et al. (2006), but vice versa in Pandithurai et al. (2009). Schofield et al. (2007) used zenith radiances at $0.9-1.7 \mu \mathrm{m}$ to observe a homogeneous cloud over Barrow, Alaska, and the cloud droplet radii derived were about 3$\mu \mathrm{m}$ larger than cloud radar retrievals. Recently, McBride et al. (2011) developed a novel method for cloud droplet size retrievals using hyperspectral measurements from the ARM shortwave spectrometer at 1-s resolution; they enhanced the sensitivity of transmittance observations to effective radius by using the spectral slope derived from measurements between 1565 and $1634 \mathrm{~nm}$. The new McBride et al. (2011) spectral method led to good agreement in both effective radius and liquid water path, when compared to satellite retrievals and ground-based microwave observations.

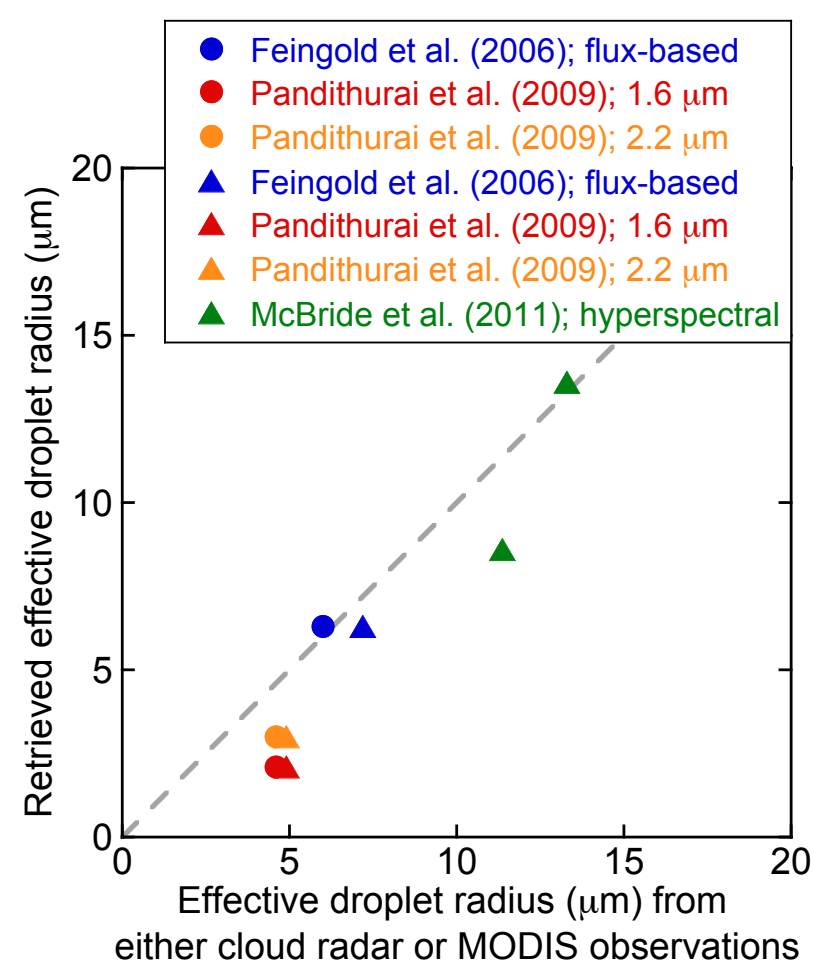

Fig. 1. Scatter plot of effective droplet radii retrieved from groundbased transmittances versus those from either ground-based cloud radar (dot) or MODIS (triangle) observations. Cloud effective radii from Feingold et al. (2006) were retrieved from combined flux and microwave measurements, and represented 3-h statistics for stratus clouds at the ARM Oklahoma site in 2003. Retrievals from Pandithurai et al. (2009) were based on multichannel zenith radiance and represented 3-day statistics for low-level, overcast ice-free water clouds at Okinawa Island, Japan in 2008; the use of liquid waterabsorbing wavelength (i.e., 1.6 or $2.2 \mu \mathrm{m}$ ) slightly changed the retrieved cloud effective radii. Similarly, retrievals from McBride et al. (2011) were based on hyperspectral zenith radiances, and compared to two MODIS overpasses for overcast water clouds at the ARM Oklahoma site in 2007.

Figure 1 summarizes the aforementioned shortwavetransmittance-based retrievals. Overall, the intercomparison results of transmittance-based retrievals with cloud radar retrievals depend strongly on radar retrieval methods; there is no clear positive or negative bias between these two types of retrievals. On the other hand, cloud droplet radii retrieved from ground-based passive observations tend to be smaller than those from satellite reflectance. This is because the ground- and satellite-based retrievals obtain their information from different levels within the cloud layer. Platnick (2000) used the number of photon scattering events to weight the contribution from each level to the overall size determination, and found that the radiative contribution mainly comes from the upper portion of the cloud layer for satellite-based retrievals. In contrast, for ground-based 
Table 1. A list of AERONET cloud-mode sites where zenith radiance measurements at $1640 \mathrm{~nm}$ are available in 2011.

\begin{tabular}{|c|c|c|c|}
\hline Site & Country & $\begin{array}{r}\text { Longitude } \\
\left(\left(^{\circ}\right)\right.\end{array}$ & $\begin{array}{r}\text { Latitude } \\
\left(\left(^{\circ}\right)\right.\end{array}$ \\
\hline ARM Darwin & Australia & 130.9 & -12.4 \\
\hline Canberra & Australia & 149.1 & -35.3 \\
\hline Ragged_Point & Barbados & -59.4 & 13.2 \\
\hline XiangHe & China & 117.0 & 39.8 \\
\hline Camaguey & Cuba & -77.8 & 21.4 \\
\hline Carpentras & France & 5.1 & 44.1 \\
\hline Lille & France & 3.1 & 50.6 \\
\hline Palaiseau & France & 2.2 & 48.7 \\
\hline Paris & France & 2.3 & 48.9 \\
\hline REUNION_ST_DENIS & France & 55.5 & -20.9 \\
\hline Hamburg & Germany & 10.0 & 53.6 \\
\hline ARM_Gan_Island & India & 73.1 & -0.7 \\
\hline ARM_Nainital & India & 79.5 & 29.4 \\
\hline IMAA_Potenza & Italy & 15.7 & 40.6 \\
\hline Nauru (ARM) & Nauru & 166.9 & -0.5 \\
\hline Manus (ARM) & Papua New Guinea & 147.4 & -2.1 \\
\hline Cabo_da_Roca & Portugal & -9.5 & 38.8 \\
\hline Graciosa (ARM) & Portugal & -28.0 & 39.1 \\
\hline Autilla & Spain & -4.6 & 42.0 \\
\hline Burjassot & Spain & -0.4 & 39.5 \\
\hline La_Laguna & Spain & -16.3 & 28.5 \\
\hline EPA-NCU & Taiwan & 121.2 & 25.0 \\
\hline Barrow & United States & -156.7 & 71.3 \\
\hline Brookhaven & United States & -72.9 & 40.9 \\
\hline Cart_Site (ARM) & United States & -97.5 & 36.6 \\
\hline GSFC & United States & -76.8 & 39.0 \\
\hline Monterey & United States & -121.9 & 36.6 \\
\hline SERC & United States & -76.5 & 38.9 \\
\hline UMBC & United States & -76.7 & 39.3 \\
\hline Univ_of_Houston & United States & -95.3 & 29.7 \\
\hline NGHIA_DO & Vietnam & 105.8 & 21.0 \\
\hline
\end{tabular}

retrievals, the contribution to the reported size comes from all levels within the cloud layer. Models from quasi-adiabatic parcel to Large Eddy, as well as in situ measurements, generally show that liquid cloud droplets grow from cloud base to cloud top, which would explain why the droplet radii from ground-based retrievals are smaller than from satellite-based retrievals.

The Aerosol Robotic Network (AERONET) recently introduced a new observation strategy, called "cloud mode", which dramatically increases the number and variety of cloud observations on a global scale (Chiu et al., 2010). AERONET is comprised of sun/sky radiometers with a $1.2^{\circ}$ field-ofview designed for aerosol retrieval. When clouds completely block the sun - making measurements of aerosol properties less practical - the radiometer switches to "cloud mode" and performs 10 zenith radiance measurements at 9-s intervals, then goes to sleep for $15 \mathrm{~min}$. Among the sites employing cloud mode shown in Fig. 2, Table 1 lists 31 AERONET sites where zenith radiance measurements also include the 1640-nm wavelength. A combination of the 1640-nm liquid water-absorbing wavelength with the others (e.g., 440, 675, 870 or $1020 \mathrm{~nm}$ ) can be used to retrieve cloud effective radius to potentially enhance the cloud mode product that currently provides retrievals only of cloud optical depth.

This paper presents a new retrieval method for cloud effective droplet radius, using zenith radiance measurements from ARM and from the AERONET cloud mode operation. In Sect. 2, we describe our retrieval method and evaluate its performance on a stratocumulus cloud from a large eddy simulation using Monte Carlo radiative transfer calculations. In Sect. 3, we introduce several ancillary observational datasets and discuss the results of the intercomparison. In particular, intercomparisons involving satellite retrievals are placed within the context of Fig. 1. Finally, Sect. 4 summarizes this paper. 


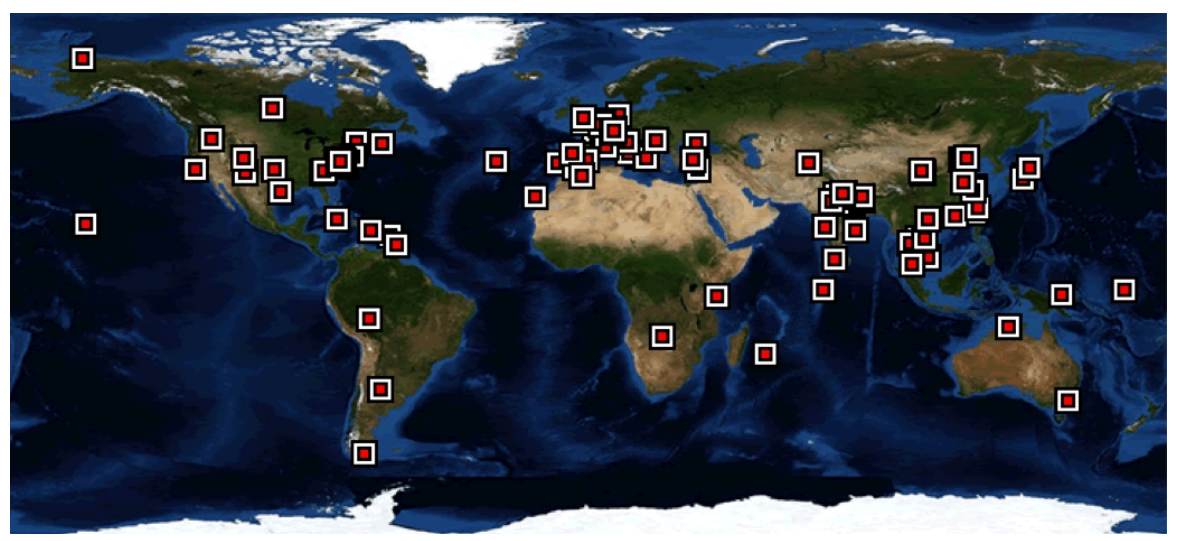

Fig. 2. AERONET cloud-mode site locations (red squares). Among these cloud-mode sites, 13 providing zenith radiance data at $1640 \mathrm{~nm}$ wavelength are listed in Table 1.

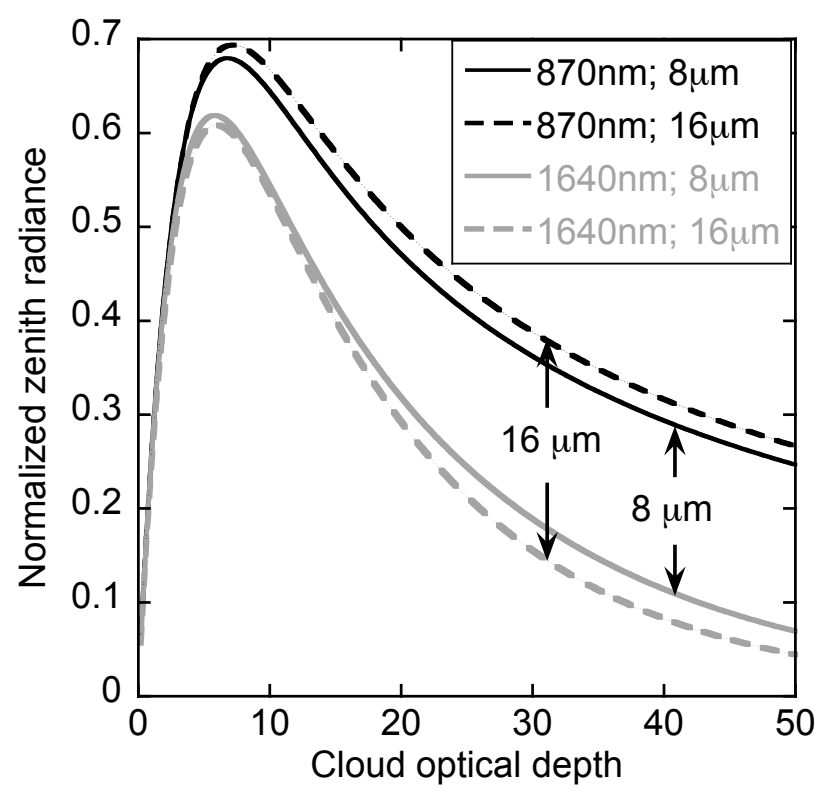

Fig. 3. Dependencies of normalized zenith radiance on cloud optical depth at 870 and $1640 \mathrm{~nm}$ wavelengths for cloud effective droplet size of 8 and $16 \mu \mathrm{m}$. Surface albedo values are 0.3 at $870 \mathrm{~nm}$, and 0.25 at $1640 \mathrm{~nm}$. Solar zenith angle is $45^{\circ}$.

\section{Methodology for retrieving cloud droplet size}

\subsection{The retrieval method}

For clouds over a Lambertian surface, the ground-based zenith radiance $I$ at a wavelength $\lambda$ is a function of cloud optical depth and effective radius. In general, it can be written as:

$I_{\lambda}=f\left(\tau_{c}, A_{\mathrm{c}}, r_{\mathrm{eff}} ; \mu_{0}, \rho_{\lambda}\right)$ where $\tau_{\mathrm{c}}$ is cloud optical depth; $A_{\mathrm{c}}$ is effective cloud fraction; $r_{\mathrm{eff}}$ is cloud effective radius; $\mu_{0}$ is the cosine of solar zenith angle; and $\rho_{\lambda}$ is the albedo of the underlying surface. To retrieve three parameters of interest (i.e., $\tau_{\mathrm{c}}, A_{\mathrm{c}}$, $\left.r_{\text {eff }}\right)$ in Eq. (1), we extended the method in Chiu et al. (2010) that used 440 and $870-\mathrm{nm}$ wavelengths by adding a 1640-nm water-absorbing wavelength.

Relationships between zenith radiance and cloud optical depth at 870 and $1640 \mathrm{~nm}$ for droplet sizes of 8 and $16 \mu \mathrm{m}$ are illustrated in Fig. 3. It is known that the larger the cloud droplets, the stronger the absorption and forward scattering. This initiates a competing process; stronger absorption for larger droplet sizes reduces zenith radiance reaching the surface, while stronger forward scattering enhances it. As a result, the zenith radiance at $870-\mathrm{nm}$ wavelength increases with droplet size due to the dominant factor of forward scattering. In contrast, the radiance at 1640-nm wavelength decreases with droplet size due to the dominant factor of absorption; however, the sensitivity of the zenith radiance to droplet size is reduced by the increase in forward scattering (Rawlins and Foot, 1990; Platnick, 2000). This implies that uncertainties in zenith radiance measurements and surface albedo estimates may have a non-negligible impact on droplet size retrievals, and, in turn, need to be accounted for in the retrieval method.

In our retrieval method, we assumed $5 \%$ uncertainty in zenith radiance measurements at all wavelengths, $5 \%$ uncertainty in surface albedo at 870 and $1640 \mathrm{~nm}$ wavelengths, and $10 \%$ uncertainty in surface albedo at $440 \mathrm{~nm}$ wavelength. These uncertainties, normally distributed and estimated from Holben et al. (1998) and Schaaf et al. (2002), are used to perturb the observed zenith radiance and surface albedo estimate, resulting in an overall relative input uncertainty of $\sim 17 \%$. We compare the perturbed zenith radiance to calculated lookup tables and search for possible solutions. The lookup tables were computed from the discrete-ordinatemethod radiative transfer model (DISORT; Stamnes et al., 1988) over reasonable ranges of cloud optical depth, effective 

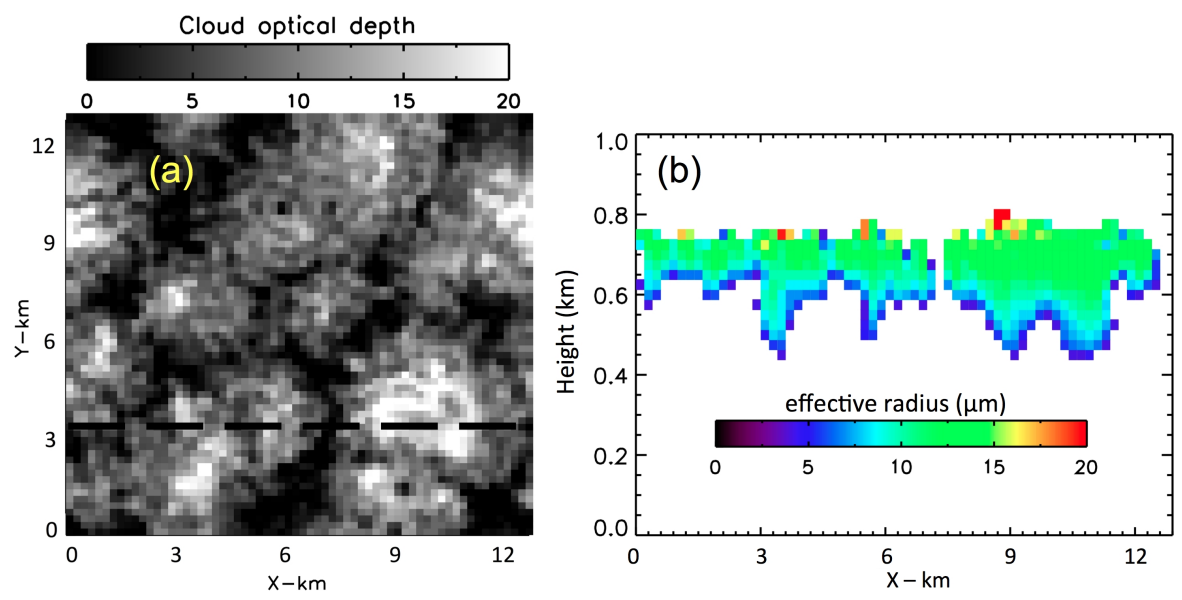

Fig. 4. (a) A Large Eddy Simulation-generated cloud optical depth field used to calculate zenith radiances that are then in turn used to test the retrieval method. Taking a cross-section along the thick black-dashed line (around $3 \mathrm{~km}$ in the y direction) gives the distribution of effective radii in the $\mathrm{x}$ - and vertical directions in (b).

cloud fraction, and cloud effective radius ranging from 4 to $20 \mu \mathrm{m}$, typical for ARM sites over Oklahoma, Alaska and Darwin (Zhao et al., 2012). We also postulate that the solution is found when zenith radiances agree with the lookup table to within $10 \%$ at both 440 and $870 \mathrm{~nm}$ wavelengths, and sort those solutions based on errors in the zenith radiance at $1640 \mathrm{~nm}$; the smaller the error, the better the solution. Finally, we take the mean of the best five solutions to produce the best solution for this particular set of the perturbed zenith radiance and surface albedo.

For each cloud-mode measurement, the above procedure is repeated 40 times using randomly generated perturbations. The final retrievals for cloud optical depth and effective radius are given as the mean of these 40 repetitions with an uncertainty estimated by the standard error. Although the thresholds of five best solutions and 40 repetitions are somewhat arbitrary, the mean bias and the root-mean-squared difference change insignificantly (about $2 \%$ ) when the thresholds increase to 10 best solutions and 1000 repetitions in the following simulation test.

\subsection{Simulations setup and evaluation metrics}

To evaluate the performance of our retrieval method, we tested simple 1-D plane-parallel clouds, as well as a more realistic stratocumulus cloud from the Intercomparison of 3-D Radiative Codes (I3RC; Cahalan et al., 2005). For both cases, the solar zenith angles were $45^{\circ}$; the surface albedo values at 440,870 and $1640 \mathrm{~nm}$ were respectively $0.05,0.3$ and 0.25 , common for a vegetated surface based on the Collection 5 products of the Terra and Aqua Moderate Resolution Imaging Spectroradiometer (MODIS) combined data set at $500 \mathrm{~m}$ resolution (Schaaf et al., 2002).

The plane-parallel cloud cases have a fixed effective radius of $10 \mu \mathrm{m}$ with various cloud optical depths, similar to set up in McBride et al. (2011). The input zenith radiances were calculated from DISORT. Table 2 shows that the relative difference between true and retrieved cloud optical depths is around $2-7 \%$, while the difference in effective radius is around 2-5\%. These errors for the ideal 1-D clouds are used as a benchmark to understand how much the retrieval error will increase in a realistic 3-D cloud, as shown next.

The I3RC stratocumulus cloud case was based on large eddy simulations of FIRE-I stratocumuli (Moeng et al., 1996; Hinkelman et al., 2007) and consisted $64 \times 64 \times 16$ cells. In this simulation test, we used two horizontal resolutions to investigate at which scale the retrieval method performs reasonably well. One set retains the original spatial resolution of the I3RC input data, $67 \times 67 \times 25 \mathrm{~m}$. By expanding grid cells horizontally but keeping the same values as the original smaller cells, we obtained the other set with resolution of $201 \times 201 \times 25 \mathrm{~m}$, close to the minimum horizontal scale where radiation measurements retain the statistics of the cloud structures (Marshak et al., 1995). Using the latter resolution, Fig. 4 shows an image of the overall cloud optical depth, and vertical features for a cross-section located at $3.1 \mathrm{~km}$ in the Y direction. As Fig. 4b shows, cloud geometric thicknesses are about $400 \mathrm{~m}$ and effective droplet radii range between 4 and $20 \mu \mathrm{m}$. Zenith radiances for this particular cross-section were simulated using a backward Monte Carlo model (similar to the model UMBC2 in Cahalan et al., 2005), with a $0^{\circ}$ solar azimuth angle.

Using this cross-section, we retrieve optical depth, cloud effective radius, and liquid water path (LWP) using the simulated zenith radiances. The former two parameters can be obtained directly from our method, but LWP needs to be calculated. One approach is

$\mathrm{LWP}=\frac{2}{3} \rho_{\mathrm{w}} \tau_{c} r_{\mathrm{eff}}$, 
Table 2. Statistics of true and retrieved cloud optical depth and effective radius for 1-D plane-parallel clouds. The solar zenith angle was $45^{\circ}$; the surface albedo values at 440, 870 and $1640 \mathrm{~nm}$ were respectively $0.05,0.3$ and 0.25 .

\begin{tabular}{rcr|rcr}
\hline & \multicolumn{2}{c|}{ Cloud optical depth } & \multicolumn{3}{|c}{ Cloud effective radius $\mathrm{r}_{\text {eff }}(\mu \mathrm{m})$} \\
True & Retrieved & Relative error $(\%)$ & True & Retrieved & Relative error $(\%)$ \\
\hline 10 & $9.8 \pm 2.4$ & -2 & 10 & $10.5 \pm 2.3$ & 5 \\
20 & $21.4 \pm 1.3$ & 7 & 10 & $9.8 \pm 2.4$ & 2 \\
40 & $42.0 \pm 1.6$ & 5 & 10 & $10.3 \pm 1.8$ & 3 \\
\hline
\end{tabular}
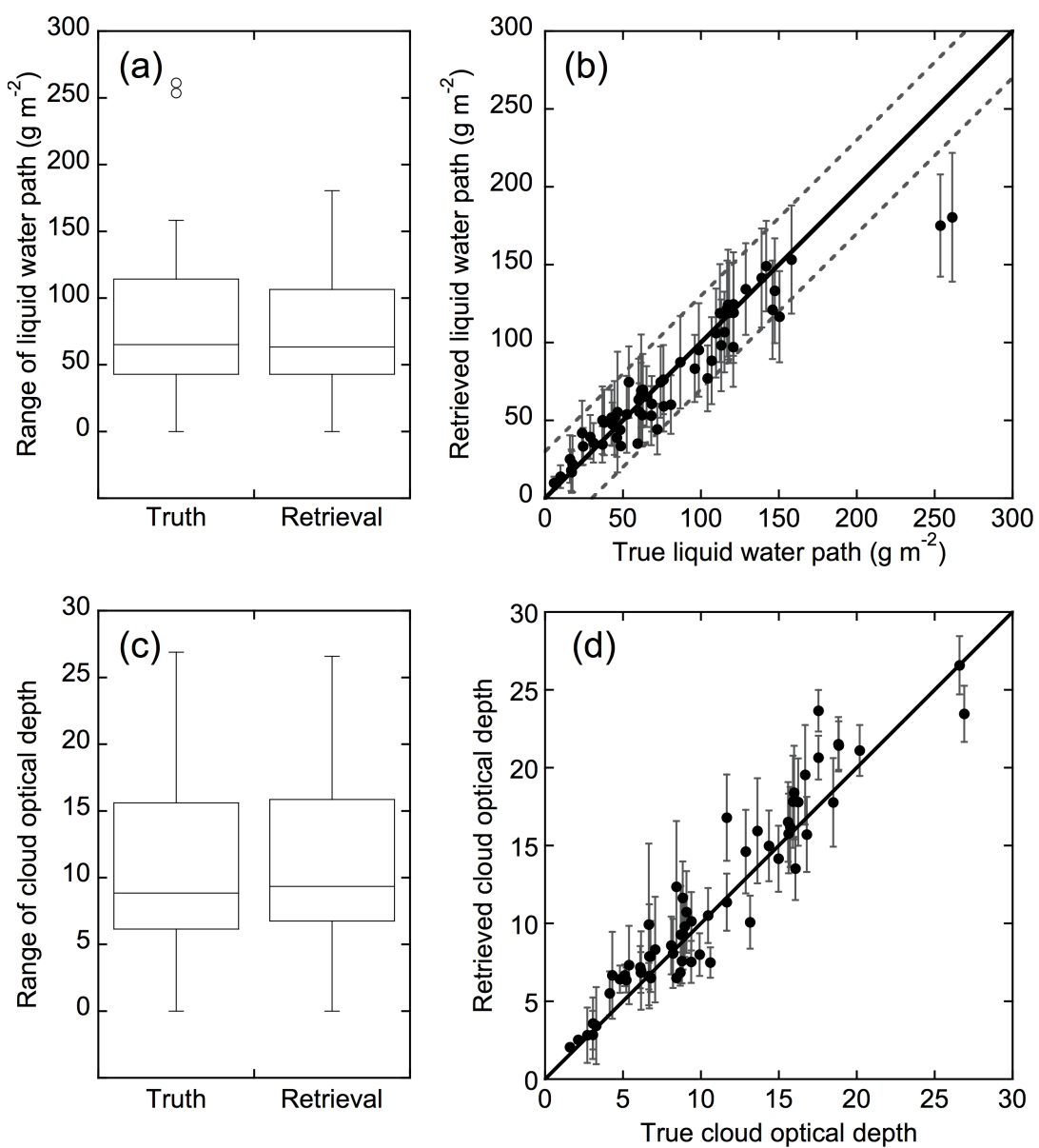

Fig. 5. Intercomparison between the true and the retrieved liquid water paths using box plot (a) and scatter plot (b), for the simulation in Fig. 4. The bottom and top of each box represent the $25 \%$ and $75 \%$ quartiles, and the line inside the box represents the median (Tukey, 1977, p. 41-43). The whiskers mark the "accepted range", which is defined as 1.5 times the interquartile distance. The open circles outside the accepted range are considered outliers. The error bars in (b) represent one standard deviation of retrievals from the 40 realizations in the retrieval process, while the co-plotted dashed lines represent a typical uncertainty of $30 \mathrm{~g} \mathrm{~m}^{-2}$ in liquid water path retrieved from microwave radiometer measurements. (c) and (d) are the same as (a) and (b), respectively, but for cloud optical depth.

where $\rho_{\mathrm{w}}$ is the density of water; this equation is based on the assumption that liquid water content (LWC) is constant in the vertical (Stephens, 1978). Another approach is

$\mathrm{LWP}=\frac{5}{9} \rho_{\mathrm{W}} \tau_{c} r_{\mathrm{eff}}$ which assumes that the droplet number concentration is approximately constant and the liquid water content increases linearly with height (Wood and Hartmann, 2006). Eq. (2) is exactly $20 \%$ larger than Eq. (3). Since in the I3RC input data the optical depth for each level was derived from Eq. (2), we used the same equation to calculate LWP from retrieved cloud optical depth and effective radius in this test. 

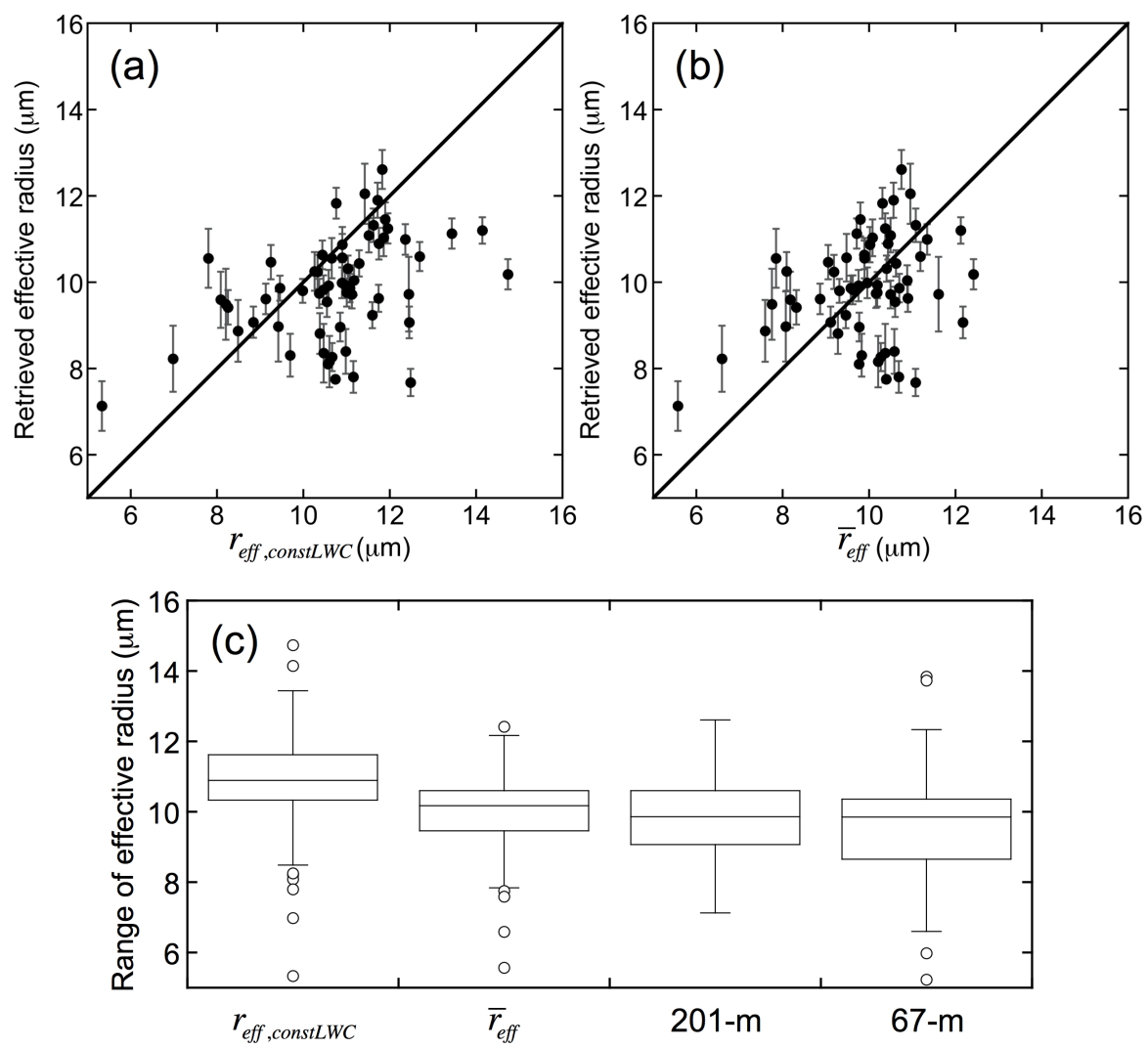

Fig. 6. Scatter plots of retrieved versus true effective radius from simulations. Two "true" effective radii are calculated: $r_{\text {eff,constLWC from }}$ the assumption of constant liquid water content in the vertical; $\bar{r}_{\text {eff }}$ from averaging droplet radii over all levels in the cloud layer. In addition, two sets of retrieved effective radii are used: one is based on simulation at $201 \mathrm{~m}$ resolution, the other is at $67 \mathrm{~m}$ resolution. (a) and (b) are

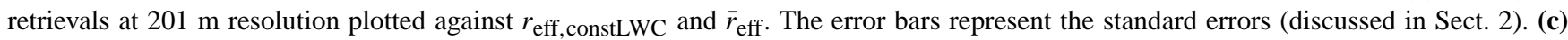
Box plots for the two types of the true effective radii, and the two sets of retrievals.

Now we need to determine the "true" column effective radius. Recall that the I3RC input data includes LWP, $\tau_{\mathrm{c}}$, and $r_{\text {eff }}$ for each level within the cloud layer. While the true total LWP and optical depth can easily be calculated by integrating the entire column, the "column cloud effective radius" cannot be unambiguously defined. One option is to use Eq. (2) to calculate $r_{\text {eff }}$ from the column-integrated LWP and the optical depth, which we refer to as $r_{\text {eff,constLwC. Another option }}$ is to use the mean effective radius $\bar{r}_{\text {eff }}$ :

$\bar{r}_{\text {eff }}=\frac{1}{N} \sum_{\text {level }=1}^{N} r_{\text {eff,level }}$,

where $r_{\text {eff, level }}$ is the effective radius at each cloud level given by the I3RC input data and $N$ is the number of the cloud levels in the cloud layer. This estimation represents the fact that for ground-based retrievals the contribution to the overall size determination is relatively uniform over the cloud layer (see Sect. 1).

Once the truth and the retrievals are generated, we use several evaluation metrics to characterize the agreement between the two: the mean bias (BIAS; the difference between the means), the root-mean-squared difference (RMSD), the linear correlation coefficient (CORR) and the relative deviation ( $\mathrm{RD}$, in \%) expressed as the ratio of the average absolute deviation to the mean value, i.e,

$$
R D=\frac{\sum_{i=1}^{M}\left|r_{\mathrm{eff}, \text { retrieved, } \mathrm{i}}-r_{\mathrm{eff}, \text { true }, i}\right|}{\sum_{i=1}^{M} r_{\mathrm{eff}, \text { true }, i}} \times 100
$$

where $M$ is the total number of data points of interest; $r_{\text {eff,true, } i}$ and $r_{\text {eff, retrieved, } i}$ are the true and retrieved effective radius at a given data point $i$, respectively.

\subsection{Evaluation results from simulations}

Let us first focus on the overall performance of the retrievals from simulations at 201-m horizontal resolution. Table 3 and Fig. 5 show that the liquid water path retrievals and the truth have similar means, standard deviations and distribution percentiles; the corresponding mean bias and RMSD are 

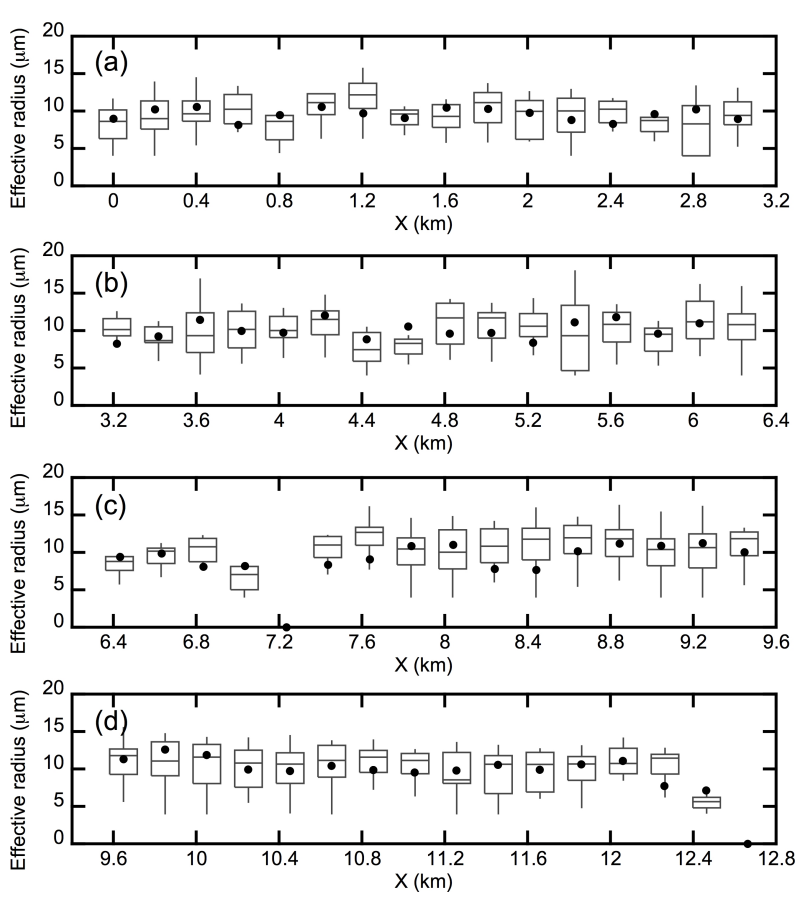

Fig. 7. Box plots of the effective radii at locations along the dashed line located at $3.1 \mathrm{~km}$ in the Y direction, as shown in Fig. 4. (ad) are one continuous plot broken into four panels. Dots are the corresponding retrievals.

$-5 \mathrm{~g} \mathrm{~m}^{-2}$ and $19 \mathrm{~g} \mathrm{~m}^{-2}$, respectively. The RMSD is comparable to the uncertainty of $20-30 \mathrm{~g} \mathrm{~m}^{-2}$ in liquid water path retrievals from two-channel microwave radiometer measurements (Marchand et al., 2003; Crewell and Löhnert, 2003). Similarly, cloud optical depth retrievals agree well with the truth; the corresponding mean bias and RMSD are 0.7 and 2, respectively.

Retrieval errors in cloud effective radius depend on which definition of the true column effective radius is used, i.e., $r_{\text {eff,constLWC }}$ from Eq. (2) or $\bar{r}_{\text {eff }}$ from Eq. (4). Table 3 and Fig. 6 show that the retrieval errors are smaller and the box plots agree better when we use $\bar{r}_{\text {eff }}$ as the truth instead of $r_{\text {eff,constLWC. However, for both situations, the correlations }}$ between the retrieved and true effective radii are weak for reasons given in Appendix A.

To check retrievals in more detail, Fig. 7 shows the box plots for all locations along the dashed line shown in Fig. 4a. Each box represents the statistical distribution of the effective radii for all levels at a given location in the $\mathrm{x}$-direction. For 62 cloudy points and two clear-sky points, only one cloudy point is not retrievable. Among the retrievable cloudy points, $80 \%$ fall between the 25th and 75th percentiles, and $60 \%$ are lower than the median. Overall, the majority of retrievals agree well with the true effective radius distributions statistically, although it remains unclear which definition of column effective radius is better.
Finally, to evaluate how retrieval performance changes with horizontal resolution, error statistics for retrievals at the 67-m horizontal resolution are summarized in Table 3. Compared to results at the 201-m horizontal resolution, the relative deviation in retrieved LWP at the smaller scale increases by $10 \%$, while the relative deviations in retrieved cloud optical depth and effective radius increase by $5 \%$.

To summarize, a better agreement has been achieved at the 201-m horizontal scale, where retrieved cloud effective radius has uncertainty $15 \%$ and RMSD $1.4-1.7 \mu \mathrm{m}$, while retrieved cloud optical depth has uncertainty $15 \%$ and RMSD 2.

\section{Comparison of cloud-mode retrievals to ARM and MODIS products}

For real world applications, we use 1.5-min-averaged zenith radiances from cloud-mode measurements to retrieve cloud optical depth and effective radius. Surface albedo estimates are obtained from MODIS collection 5 products (Schaaf et al., 2002). When these are not available, we use an optimized climatological database derived from 2000-2004, 16 day average MODIS surface reflectivity product at 1 min resolution (Moody et al., 2005, 2007; Eck et al., 2008). The resulting cloud-mode retrievals are then compared to several products from ARM and MODIS during May 2007-June 2008. We focus on the ARM Oklahoma site due to the superior availability of its data products, including LWP from microwave radiometer measurements, and cloud effective radius from flux and radar measurements.

\subsection{LWP comparison to ARM microwave- and infrared-based retrievals}

In this section, we evaluate cloud-mode LWP retrievals against the ARM Archive MWRRET product (Turner et al., 2007). MWRRET optimizes LWP estimates by blending radiative transfer calculations with radiosonde measurements and with microwave radiometer measurements having a $5.9^{\circ}$ field-of-view and 20-s time resolution. This physical-based method significantly reduced the clear-sky bias, a common problem in all earlier retrieval techniques. In general, the retrieval uncertainty from MWRRET is $20-30 \mathrm{~g} \mathrm{~m}^{-2}$.

Since microwave radiometers mainly detect liquid clouds and retrievals are unreliable during precipitating periods, we excluded rainy cases using rain gauge measurements, and ice cloud cases using Cloudnet products (Illingworth et al., 2007). Cloudnet provides ice water content at 30 -s time resolution and $90-\mathrm{m}$ vertical resolution, using cloud radar reflectivity measurements and temperature profile information (Hogan et al., 2006). Although the retrieval uncertainty in ice

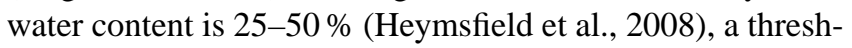
old of zero ice water content has been applied for our ice cloud exclusions. 

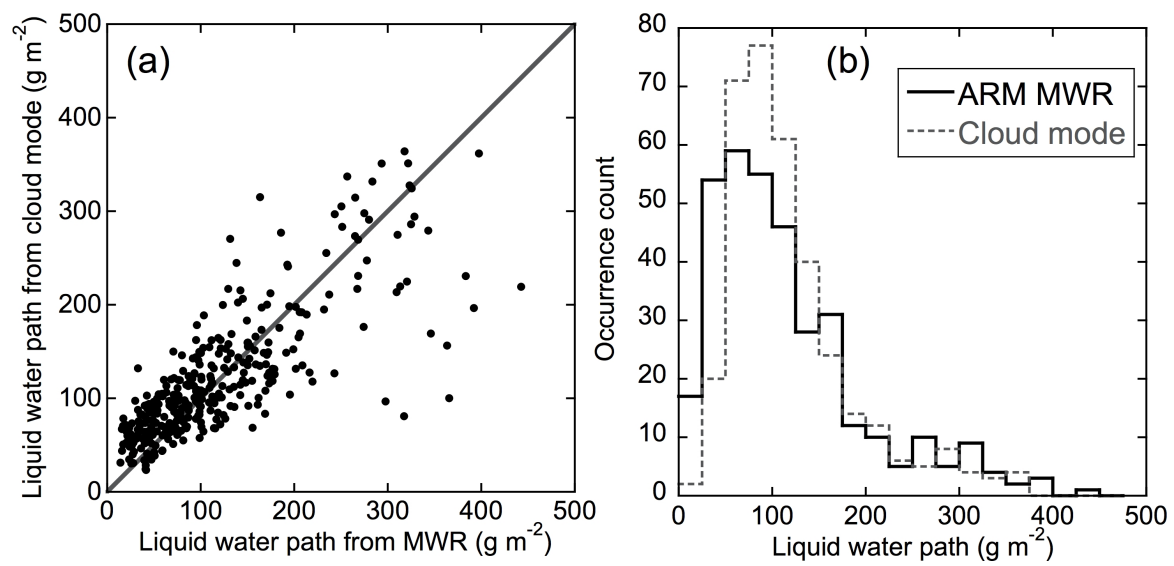

Fig. 8. (a) Scatter plot of liquid water paths retrieved from the ARM microwave radiometer (MWR; Turner et al., 2007) versus coincident cloud-mode measurements at 1.5-min temporal resolution for all liquid water clouds during May 2007-June 2008. Cloud-mode LWP values are calculated from retrieved cloud optical depth and effective radius, assuming that cloud droplet concentration is approximately constant and that liquid water content increases linearly with height. (b) The corresponding occurrence counts using a bin size of $25 \mathrm{~g} \mathrm{~m}{ }^{-2}$.

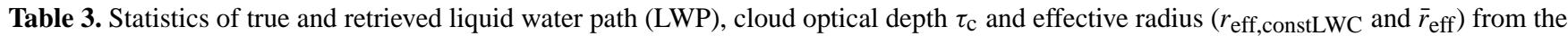
simulations at $201 \mathrm{~m}$ and $67 \mathrm{~m}$ horizontal resolution presented in Sect. 2; mean and standard deviation are included in each parenthesis. The other columns represent mean bias (BIAS), root-mean-squared difference (RMSD), relative deviation (RD in \%) and correlation coefficient (CORR).

\begin{tabular}{|c|c|c|c|c|c|c|}
\hline Variable & Truth & Retrieval & BIAS & RMSD & $\mathrm{RD}(\%)$ & CORR \\
\hline \multicolumn{7}{|c|}{ Based on simulations at $201 \mathrm{~m}$ resolution } \\
\hline $\operatorname{LWP}\left(\mathrm{g} \mathrm{m}^{-2}\right)$ & $(81 \pm 52)$ & $(76 \pm 42)^{\mathrm{a}}$ & -5 & 19 & 14 & 0.95 \\
\hline$\tau_{\mathrm{c}}$ & $(10.7 \pm 5.8)$ & $(11.4 \pm 6.0)$ & 0.7 & 2.0 & 14 & 0.95 \\
\hline$r_{\text {eff,constLWC }}(\mu \mathrm{m})$ & $(10.7 \pm 1.6)^{\mathrm{b}}$ & $(9.9 \pm 1.2)$ & -0.8 & 1.7 & 13 & 0.43 \\
\hline $\bar{r}_{\mathrm{eff}}(\mu \mathrm{m})$ & $(9.91 \pm 1.25)^{\mathrm{c}}$ & $(9.85 \pm 1.19)$ & -0.06 & 1.4 & 12 & 0.32 \\
\hline \multicolumn{7}{|c|}{ Based on simulations at $67 \mathrm{~m}$ resolution } \\
\hline $\operatorname{LWP}\left(\mathrm{g} \mathrm{m}^{-2}\right)$ & $(81 \pm 52)$ & $(68 \pm 30)^{\mathrm{a}}$ & -13 & 34 & 25 & 0.86 \\
\hline$\tau_{\mathrm{c}}$ & $(10.7 \pm 5.8)$ & $(11.2 \pm 5.7)$ & 0.5 & 3.0 & 19 & 0.88 \\
\hline$r_{\text {eff,constLWC }}(\mu \mathrm{m})$ & $(10.7 \pm 1.6)^{b}$ & $(9.6 \pm 1.6)$ & -1.1 & 2.7 & 20 & 0.20 \\
\hline $\bar{r}_{\mathrm{eff}}(\mu \mathrm{m})$ & $(9.9 \pm 1.3)^{\mathrm{c}}$ & $(9.6 \pm 1.6)$ & -0.3 & 2.4 & 18 & 0.30 \\
\hline
\end{tabular}

The LWP values from the MWRRET product during May 2007-June 2008 range between 10 and $450 \mathrm{~g} \mathrm{~m}^{-2}$ with a mean of $117 \mathrm{~g} \mathrm{~m}^{-2}$ and one standard deviation of $83 \mathrm{~g} \mathrm{~m}^{-2}$. For intercomparison, we used Eqs. (2) and (3) to calculate retrieved LWP. Table 4 shows that the use of Eq. (3) significantly reduces the bias from 28 down to $4 \mathrm{~g} \mathrm{~m}^{-2}$, and slightly reduces the RMSD from 60 to $50 \mathrm{~g} \mathrm{~m}^{-2}$. This indicates that cloud water content more likely increases with height at the ARM Oklahoma site, consistent with the findings of McBride et al. (2011).

To take a more detailed look, Fig. 8a shows that LWP retrievals calculated from Eq. (3) correlate well to MWRRET. Fig. $8 \mathrm{~b}$ shows that histograms from the two methods peak at $50-100 \mathrm{~g} \mathrm{~m}^{-2}$, but the occurrence of low LWP values is much more frequent in MWRRET than in cloud mode. Although this discrepancy might be partly due to the difference in field-of-view and observation strategy, it requires other datasets to understand the cause.

\subsection{Cloud effective radius comparison to ARM radar-based retrievals}

A continuous dataset for cloud effective radius at a time resolution of $5 \mathrm{~min}$ and a vertical resolution of $90 \mathrm{~m}$ is available in the ARM Archive, based on merging measurements of cloud radar, microwave radiometer and radiosonde 
Table 4. Statistics for comparison of liquid water path $\left(\mathrm{g} \mathrm{m}^{-2}\right)$ between the new cloud-mode retrievals and retrievals from the ARM microwave radiometer (MWR) during May 2007-June 2008. Descriptions of these metrics can be found in Table 3 (but here BIAS is computed treating the MWR as truth). The ARM product used for this analysis is called MWRRET in the archive. Cloud-mode LWP is calculated from retrieved cloud optical depth and effective radius using two approaches.

\begin{tabular}{lccccc}
\hline $\begin{array}{l}\text { ARM MWR LWP } \\
\left(\mathrm{g} \mathrm{m}^{-2}\right)\end{array}$ & $\begin{array}{c}\text { Cloud-mode LWP } \\
\left(\mathrm{g} \mathrm{m}^{-2}\right)\end{array}$ & $\begin{array}{c}\text { BIAS } \\
\left(\mathrm{g} \mathrm{m}^{-2}\right)\end{array}$ & $\begin{array}{c}\text { RMSD } \\
\left(\mathrm{g} \mathrm{m}^{-2}\right)\end{array}$ & $\begin{array}{c}\text { RD } \\
(\%)\end{array}$ & CORR \\
\hline$(117 \pm 83)$ & $(145 \pm 82)^{\mathrm{a}}$ & 28 & 60 & 38 & 0.8 \\
& $(121 \pm 68)^{\mathrm{b}}$ & 4 & 50 & 30 & 0.8 \\
\hline
\end{tabular}

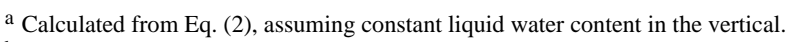

b Calculated from Eq. (3), assuming an approximately constant cloud droplet concentration and a linear increase in liquid water content with height.
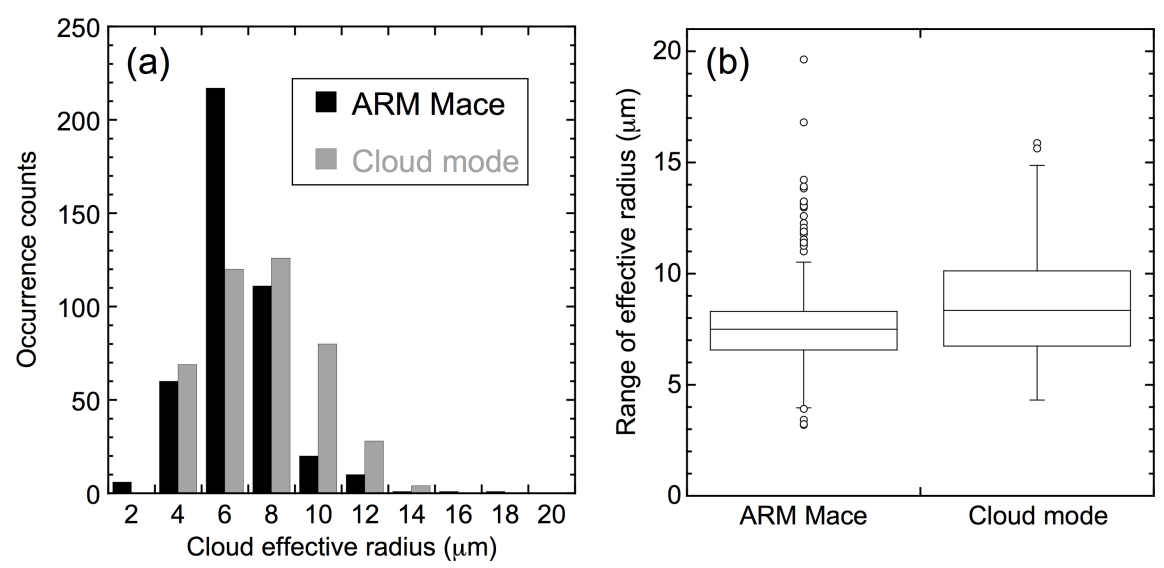

Fig. 9. Intercomparison of cloud effective radius retrieved from cloud mode to those from the ARM Mace dataset by showing (a) the histograms of the occurrence counts, and (b) the box plots. Note that cloud-mode retrievals represent a 1.5-min average droplet radius, while the ARM Mace retrievals represent a 5-min average radius.

soundings (Mace et al., 2006). For daytime retrievals, the effective radius of liquid clouds at cloud base is estimated from an empirical relationship using liquid water path and solar transmission (Dong et al., 1998). The effective radius at cloud base is then used to estimate the vertical distribution of effective radius based on the observed radar reflectivity profile (Dong and Mace, 2003). We call this dataset "ARM Mace" hereafter.

Cloud radar data in ARM Mace were excluded from comparison based on several factors: (1) when solar zenith angle was greater than $70^{\circ} ;(2)$ when rain gauge data showed non-zero rain rate; (3) when the window of the microwave radiometer was wet; and (4) when ice water contents were non-zero. After these exclusions, mean effective radii were calculated by averaging over all levels within the cloud layer.

Occurrence histograms of cloud effective radii from cloud mode and coincident ARM Mace retrievals are shown in Fig. 9. The occurrence frequency of ARM Mace 5-min average effective radii peaks at $6-8 \mu \mathrm{m}$, while the frequency of cloud-mode retrievals peaks at $8-10 \mu \mathrm{m}$. Cloud-mode retrievals also show a much higher occurrence frequency at 10$14 \mu \mathrm{m}$ compared to the Mace dataset. This in turn leads to a significant difference in the overall mean in Fig. 9b, where we see that effective radii retrieved from the ARM Mace and cloud-mode datasets are respectively (7.6 \pm 1.8$)$ and $(8.5 \pm 2.2) \mu \mathrm{m}$. The bias of $\sim 1 \mu \mathrm{m}$ is smaller than those reported in Schofield et al. (2007) and Pandithurai et al. (2009), but similar to those reported in Kikuchi et al. (2006), as discussed in Sect. 1.

Since cloud properties are scale-dependent, the bias of $\sim 1 \mu \mathrm{m}$ is partly due to the fact that these two retrievals represent different time scales. Unfortunately, 5-min average cloud-mode retrievals cannot be derived due to less frequent cloud-mode observations, which are dependent on the $\sim 15$ min direct sun measurement frequency (Holben et al., 1998). To identify the source of the discrepancy, we will need to either change cloud-mode observation strategy or do radar retrievals with higher time resolution. 

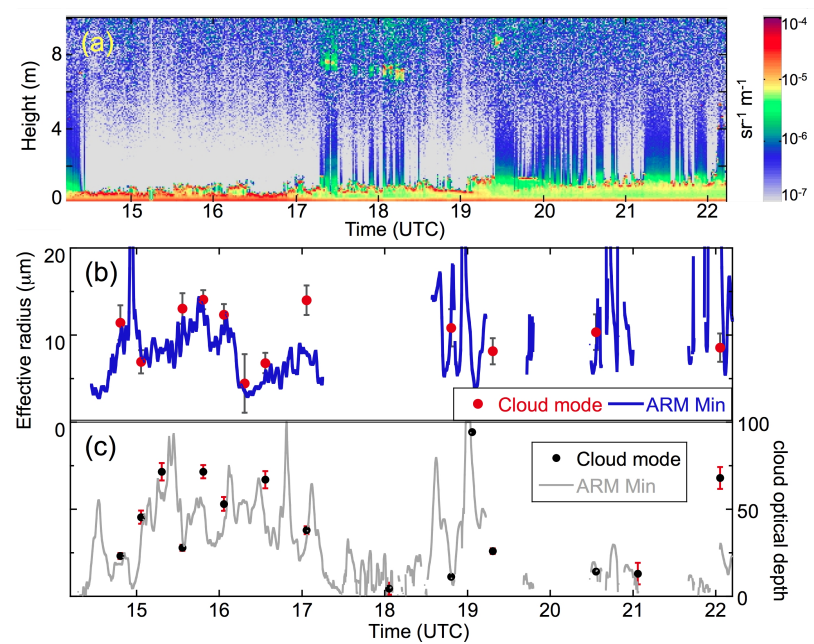

Fig. 10. (a) Attenuated backscatter signal from micropulse lidar on 15 June 2007. A time series of effective radius (b) and cloud optical depth (c) from cloud-mode measurements and the ARM Min dataset. The error bars represent one standard deviation. In (b), we omit the default values of $8 \mu \mathrm{m}$ reported in the ARM Min retrievals. In (c), cloud optical depth from the ARM Min dataset was truncated at 100 for plotting purposes.

\subsection{Cloud effective radius comparison to ARM flux-based retrievals}

In this section, we evaluate cloud-mode effective radii against the ARM product that is based on shortwave flux measurements. The ARM multifilter rotating shadowband radiometer (MFRSR), with a hemispheric FOV, provides 20sec averages of both direct and diffuse solar flux in narrow bands centered at 415, 500, 615, 673, 870, and $940 \mathrm{~nm}$. Min and Harrison (1996a) used direct and diffuse transmittance at $415 \mathrm{~nm}$ to estimate cloud optical depth with an initial default effective radius of $8 \mu \mathrm{m}$. With additional liquid water paths retrieved from the ARM microwave radiometers, cloud effective radius and optical depth can be simultaneously retrieved by minimizing least-squares errors in radiance along with an adjoint radiative transfer method (Min and Harrison, 1996b; Min et al. 2003). If the error minimum can't be found, the default $8-\mu \mathrm{m}$ size is reported and is excluded in our intercomparison. In addition, to match the temporal resolution of AERONET cloud-mode retrievals, effective radius values from the ARM dataset are averaged to a 1.5 min time window. We call this dataset "ARM Min" hereafter.

Results for a 15 June 2007 case are investigated as shown in Fig. 10. The plot of lidar backscatter coefficients shows that liquid layers severely attenuate the signal during 14:0017:00 and 18:00-19:00 UTC, indicating the presence of optically thick low clouds. It also shows occasional high clouds during 17:00-18:00 and after 19:00 UTC. Figure 10b and c show that in the time periods of continuous low clouds, retrievals of both cloud effective radius and optical depth from cloud mode and ARM Min datasets agree reasonably well, except near 17:00 UTC when cloud optical depth decreased dramatically from 100 to 25 and cloud-mode effective radius is higher by $\sim 4 \mu \mathrm{m}$. For time periods when clouds are less homogeneous (like the case around 17:00 UTC just mentioned), droplet radii from the two datasets are significantly different.

To extend our comparison to all non-precipitating and relatively homogeneous liquid clouds, we first used rain gauge data to exclude rainy periods. We further excluded the time period when cloud gaps were present, by requiring the ARM Min retrievals of optical depth to be continuously greater than 10 for at least one hour. We also excluded time periods when cloud optical depths fluctuated significantly, by checking whether the corresponding standard deviation exceeded 10. Finally, we excluded overlying ice cloud cases using Cloudnet products and the procedure described in Sect. 3.1.

For non-precipitating and relatively homogeneous liquid clouds, Fig. 11a shows that cloud optical depths agree well with those from the ARM Min dataset, with a correlation coefficient 0.96 . Generally, cloud optical depths from cloud mode are larger than those from ARM Min by a mean difference of 3; the corresponding RMSD and relative deviation are 5.5 and $13 \%$, respectively (Table 5). In contrast, the correlation in cloud effective radius shown in Fig. 11b is low (0.3), even though the mean and standard deviation of effective radius from the two are nearly identical. This is explained in Appendix A. The corresponding RMSD of $2.6 \mu \mathrm{m}$ and the relative deviation of $22 \%$ in effective radius retrievals are larger than the uncertainty estimated from our simulation test (Table 3).

\subsection{Cloud effective radius comparison to MODIS reflectance-based retrievals}

In this section, we evaluate cloud-mode effective radii against MODIS Level 2 cloud products (Collection 5), which provide cloud effective droplet radius and cloud phase at $1 \mathrm{~km}$ resolution. We used droplet radii retrieved from the MODIS $2.1 \mu \mathrm{m}$ wavelength, which agreed with those retrieved from the $3.7 \mu \mathrm{m}$ wavelength to within $2 \mu \mathrm{m}$ for relatively homogeneous clouds (Zhang and Platnick, 2011). For our intercomparison, relatively homogenous cases were selected when cloud optical depths from the ARM Min dataset were continuously greater than 10 for at least one hour.

Similar to Chiu et al. (2010), we have chosen 1-h time windows centered at the MODIS overpass times for our intercomparison; the number of MODIS pixels was determined by the wind speed at the cloud base height. In addition, we used MODIS retrievals only when their corresponding cloud phase is liquid water. We also used cloud-mode retrievals only when MODIS measurement times were ice-free based on Cloudnet products. As a result, eight Terra and Aqua overpasses during May-December 2007 are used and listed in Table 6. 
Table 5. Statistics for comparison of liquid water path, cloud optical depth and effective radius between the new cloud-mode retrievals and the ARM flux-based retrievals. Mean and standard deviation are included in each parenthesis. Cases are limited to non-precipitating and relatively homogeneous clouds during May 2007-June 2008.

\begin{tabular}{lcccccc}
\hline Variable & ARM Min & Cloud mode & BIAS & RMSD & RD $(\%)$ & CORR \\
\hline LWP $\left(\mathrm{g} \mathrm{m}^{-2}\right)$ & $(132 \pm 54)$ & $(148 \pm 71)^{*}$ & 16 & 46 & 26 & 0.80 \\
Cloud optical depth & $(30 \pm 13)$ & $(33 \pm 15)$ & 3 & 5.5 & 13 & 0.96 \\
Effective radius $(\mu \mathrm{m})$ & $(8.2 \pm 2.2)$ & $(8.3 \pm 2.2)$ & 0.1 & 2.6 & 22 & 0.30 \\
\hline
\end{tabular}

* Calculated from the retrieved cloud optical depth and effective radius assuming an approximately constant cloud droplet concentration and a linear increase in liquid water content with height.

Table 6. Information on Terra/Aqua MODIS overpasses at the ARM Oklahoma site in 2007 used for evaluations of cloud-mode retrievals.

\begin{tabular}{lccr}
\hline $\begin{array}{l}\text { Overpass } \\
\text { index }\end{array}$ & Date & $\begin{array}{c}\text { Time } \\
(\mathrm{UTC})\end{array}$ & $\begin{array}{r}\text { Cloud base height } \\
*(\mathrm{~m})\end{array}$ \\
\hline Terra & & & \\
\hline 1 & $15 \mathrm{May}$ & $17: 40$ & 880 \\
2 & $25 \mathrm{Aug}$ & $17: 05$ & 720 \\
3 & $14 \mathrm{Sep}$ & $16: 40$ & 1080 \\
4 & $15 \mathrm{Sep}$ & $17: 25$ & 690 \\
5 & 12 Dec & $16: 35$ & 3510 \\
\hline Aqua & & & 1480 \\
\hline 6 & 5 May & $20: 20$ & 1080 \\
7 & 10 Sep & $20: 20$ & 106 \\
8 & 14 Dec & $19: 35$ & \\
* Estimated from ARM's Active Remotely Sensed Clouds Locations \\
(ARSCL) product.
\end{tabular}

The box plot in Fig. 12 shows that all cloud-mode points fall into the whiskers if not always the boxes of MODIS retrievals, and $75 \%$ of points are in the lower percentile of the satellite retrieval distributions. As discussed in Sect. 1, satellite-based effective radius retrievals are mainly determined by droplet sizes nearer to the cloud tops, while ground-based retrievals are affected by all cloud layers. Thus, we expect cloud-mode retrievals to be distributed in the lower 50th percentile of the satellite retrieval range, which is consistent with the behavior seen in Fig. 12. Overall, Table 7 shows a bias of $-0.9 \mu \mathrm{m}$ and a relative deviation of $11 \%$ between the two sets of retrievals. Note that uncertainties in cloud-mode retrievals can be $15 \%$ based on our simulation test, and uncertainties in MODIS retrievals can be 5$20 \%$ due to cloud inhomogeneity (Nakajima et al., 1991; Platnick and Valero, 1995). Painemal and Zuidema (2011) also reported a $15-20 \%$ overestimate of MODIS retrievals compared to in-situ data for stratocumulus clouds. These reported uncertainties help conclude that cloud-mode retrievals agree reasonably well with MODIS for relatively homogenous clouds.
Finally, the means of cloud-mode and MODIS retrievals for each overpass are plotted in Fig. 13, along with those reported in literature (similar to Fig. 1). In general, our overcast cases fall into the radius range between 9 and $13 \mu \mathrm{m}$. Some cloud-mode points are close to the one-to-one diagonal line, similar to the points in McBride et al. (2011); some have slight deviations from MODIS retrievals, similar to the point in Feingold et al. (2006).

\section{Summary}

We developed a new retrieval method for cloud effective droplet radius using ground-based zenith radiances taken from the ARM program and the NASA AERONET. The method takes advantage of the additional $1640 \mathrm{~nm}$ wavelength that has recently become standard for monitoring aerosol properties in AERONET. Specifically, we used 440, 870 and $1640 \mathrm{~nm}$ wavelengths to simultaneously retrieve cloud optical depth and effective droplet size, based on the fact that radiance at the first two wavelengths is mainly determined by cloud optical depth, while at the last wavelength it is mainly determined by droplet size.

We conducted extensive tests using simulations, groundand satellite-based measurements for non-precipitating liquid water clouds. First, we tested the retrieval method on a simulated stratocumulus cloud at two different spatial scales, 67 and $201 \mathrm{~m}$. The cross-section we took for evaluation represented clouds with LWP less than $300 \mathrm{~g} \mathrm{~m}^{-2}$, and effective radii ranging between 4 and $20 \mu \mathrm{m}$. Overall, a better agreement was achieved for the 201-m spatial scale; the retrieval uncertainty in cloud effective radius is $13 \%$ and the RMSD is $1.7 \mu \mathrm{m}$. At the $67-\mathrm{m}$ spatial scale, errors of LWP increase by $10 \%$, and errors of cloud effective radius and optical depth increase by $5 \%$.

Second, we compared our retrievals to those from cloud radar and microwave measurements. For clouds with liquid water path less than $450 \mathrm{~g} \mathrm{~m}^{-2}$, better agreement has been achieved under the assumption that liquid water content increases linearly with height; the retrieval uncertainty in liquid water path is $30 \%$ and the root-mean-squared error is $50 \mathrm{~g} \mathrm{~m}^{-2}$. In addition, coincident cloud-mode and ARM cloud radar retrievals have shown that the latter has 

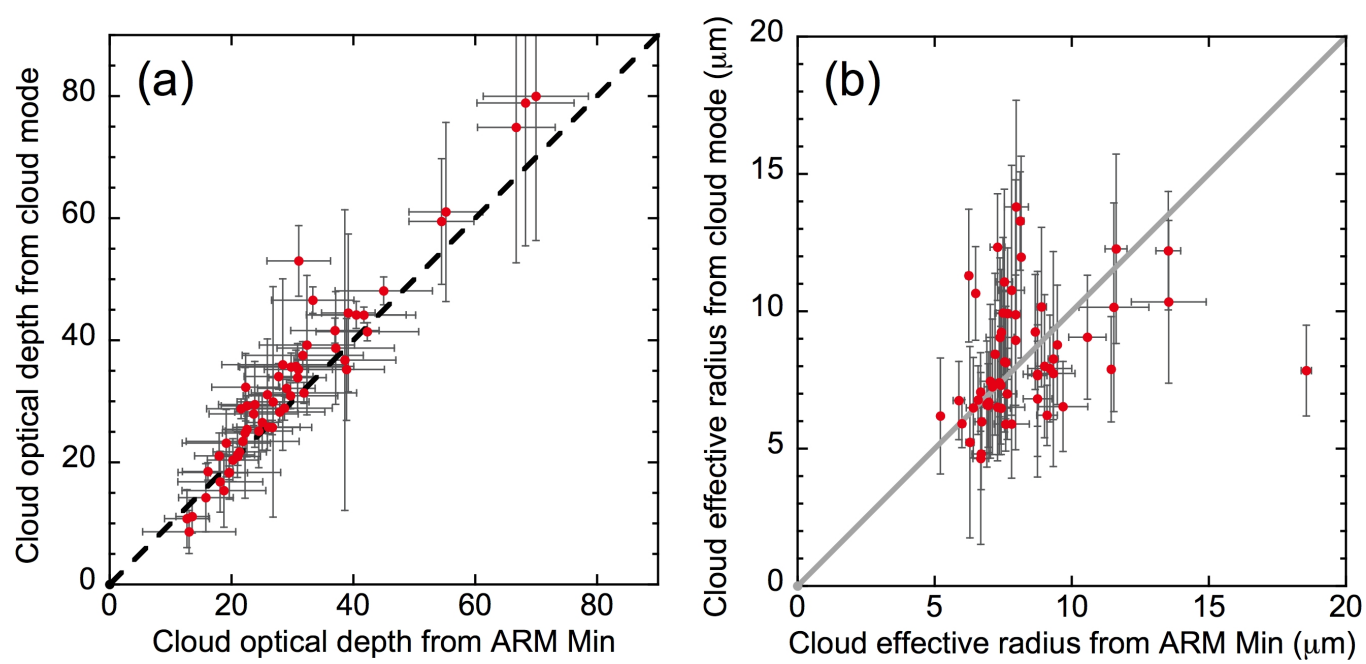

Fig. 11. Scatter plots of 1.5-min average cloud optical depth (a) and effective radii (b) retrieved from cloud mode versus those from the ARM Min dataset. Error bars for the ARM Min dataset represent one standard deviation of retrievals during 1-h time windows.

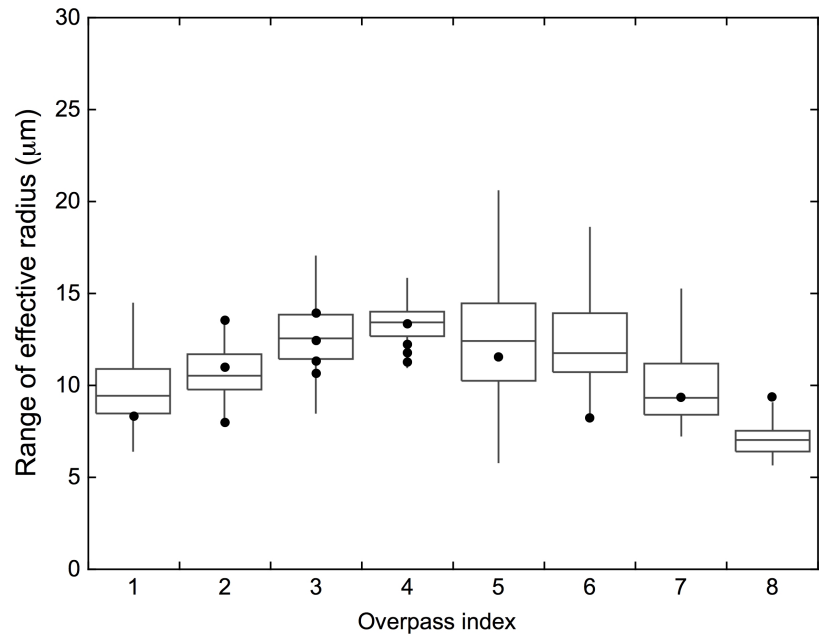

Fig. 12. Box plots of cloud effective droplet radii retrieved from Terra/Aqua MODIS at the ARM Oklahoma site in 2007. Coplotted dots represent cloud-mode 1.5-min average effective radius during the 1-h time window centred at the MODIS overpass time. Detailed information for each overpass can be found in Table 6 .

a narrower peak at $6-8 \mu \mathrm{m}$ than the former which peaks at $6-10 \mu \mathrm{m}$. The overall bias is $1 \mu \mathrm{m}$, comparable to that reported in Kikuchi et al. (2006).

Third, we compared our retrievals to those from flux and microwave combined measurements for relatively homogeneous clouds. Our retrieval uncertainty in liquid water path is $26 \%$ and the RMSD is $46 \mathrm{~g} \mathrm{~m}^{-2}$, similar to the finding for all-liquid-water clouds. This is not surprising because effective radii from the flux-based method were constrained by
Table 7. Statistics for comparison of cloud effective droplet radius $(\mu \mathrm{m})$ to MODIS retrievals using eight Terra and Aqua overpasses in May-December 2007. Mean and standard deviation are included in each parenthesis. The metrics include the mean bias (BIAS), rootmean-squared difference (RMSD), relative deviation (RD in \%) and correlation (CORR).

\begin{tabular}{lccccc}
\hline $\begin{array}{l}\text { MODIS } \\
(\mu \mathrm{m})\end{array}$ & $\begin{array}{c}\text { Cloud mode } \\
(\mu \mathrm{m})\end{array}$ & $\begin{array}{c}\text { BIAS } \\
(\mu \mathrm{m})\end{array}$ & $\begin{array}{c}\text { RMSD } \\
(\mu \mathrm{m})\end{array}$ & $\begin{array}{c}\text { RD } \\
(\%)\end{array}$ & CORR \\
\hline$(11.2 \pm 1.5)$ & $(10.3 \pm 1.6)$ & -0.9 & 1.8 & 11 & 0.5 \\
\hline
\end{tabular}

microwave observations. The retrieval uncertainty in cloud effective radius is $22 \%$ and the RMSD is $2.6 \mu \mathrm{m}$; these values are larger than those suggested by the simulation case. Interestingly, even though a low correlation coefficient is obtained in cloud effective radius between the two retrieval sets, the bias of $0.1 \mu \mathrm{m}$ between the two retrieval sets is negligible. This is explained in Appendix A.

Finally, we compared our retrievals to satellite-based retrievals that have been widely used for cloud study. Cloudmode retrieval uncertainty in effective droplet radius is $11 \%$ and the RMSD is $1.8 \mu \mathrm{m}$. In particular, cloud-mode retrievals have a negative bias of $0.9 \mu \mathrm{m}$, compared to satellite data. This negative bias can be attributed to the fact that cloud droplet effective radius increases with height for liquid layers under quasi-adiabatic conditions; ground-based retrievals receive an equal contribution to the layer-averaged cloud droplet effective radius from all levels within the cloud layer, whereas the dominant contribution for satellite-based retrievals is from the cloud top. 


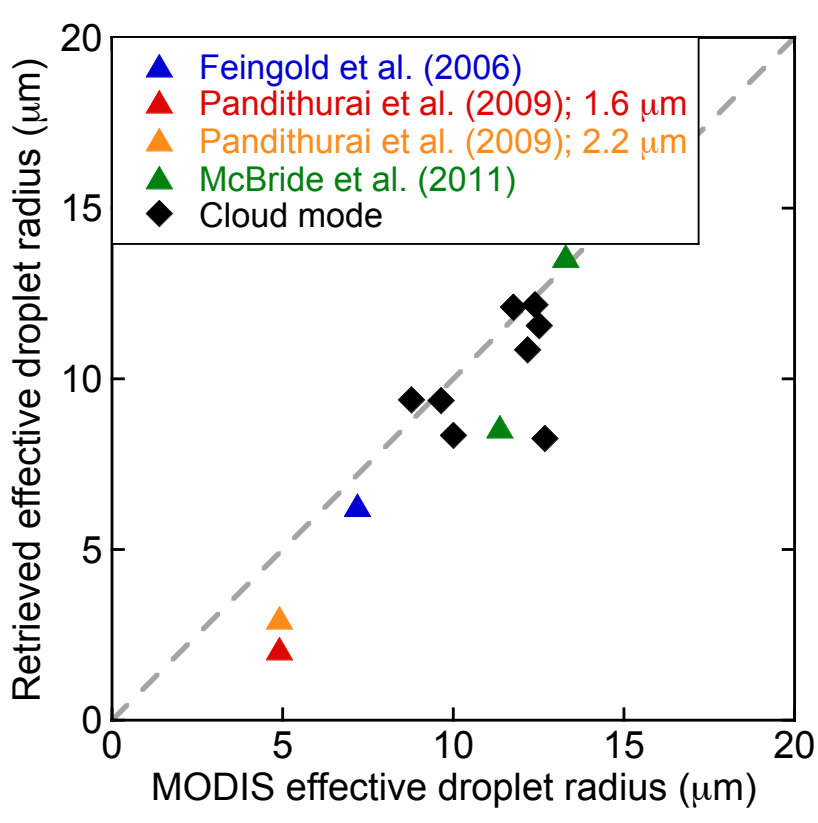

Fig. 13. Same as Fig. 1, but for intercomparison to MODISretrieved cloud effective droplet radii only. Cloud-mode retrievals are based on eight cases listed in Table 6.

Overall, for non-precipitating liquid water clouds, the retrieval uncertainty is $11-22 \%$ for cloud effective radius and $14-30 \%$ for liquid water path based on a simulated stratocumulus case and on ground and satellite measurements. For the ARM Oklahoma site, the assumption of a linear increase in liquid water content with height appears to be suitable for all clouds. At other sites, caution must be exercised, with additional intercomparisons against microwave observations necessary to determine an appropriate assumption for the vertical distribution of liquid water content.

\section{Appendix A}

Understanding the impact of retrieval accuracy and dynamic range on correlation

The correlation between the truth and the retrievals is determined not only by the retrieval accuracy, but also by the dynamic range of the retrieval variable. In our simulation test, the majority of cloud effective radii range between 8 and $12 \mu \mathrm{m}$. For such small dynamic range, achievement of a high correlation coefficient requires high retrieval accuracy, which is illustrated next using synthetic data.
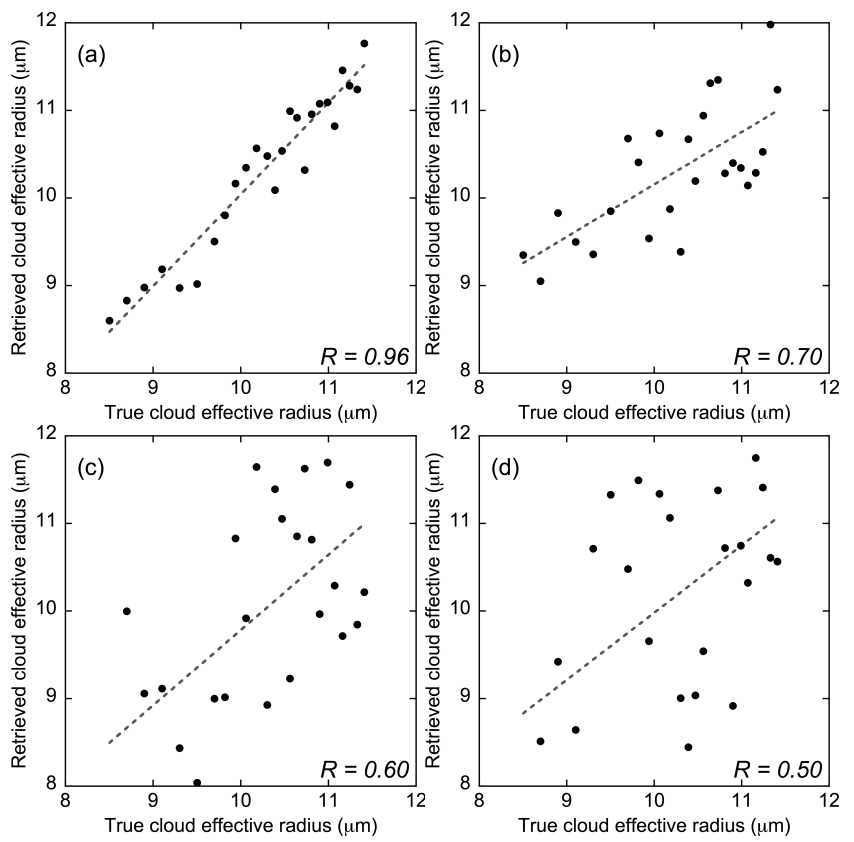

Fig. A1. Plots of the retrievals versus the truth, assuming that the retrievals agree to the truth within an error of (a) $0.5 \mu \mathrm{m}$, (b) 1.0 $\mu \mathrm{m}$, (c) $1.5 \mu \mathrm{m}$, (d) $2.0 \mu \mathrm{m}$. The corresponding correlation coefficient $(R)$ is listed in each plot.

Suppose that retrievals agree to the truth within an error of $\varepsilon$. We randomly generated retrievals by

$r_{\text {retrieve }}=r_{\text {true }}+\varepsilon \cdot(2 \alpha-1)$,

where $\alpha$ is a random variable uniformly distributed between 0 and $1 ; r_{\text {true }}$ and $r_{\text {retrieve }}$ represent the truth and its retrieved counterpart, respectively. Figure A1 shows that the correlation coefficient between $r_{\text {true }}$ and $r_{\text {retrieve }}$ decreases with increasing error of $\varepsilon$. When the error is comparable to the dynamic range, the correlation automatically becomes weak as shown in Fig. A1c and d. Our retrieval uncertainty is on the order of $1.5 \mu \mathrm{m}$ and comparable to an overall uncertainty in input data of $17 \%$. The error interval $(\sim 3 \mu \mathrm{m})$ however is comparable to the dynamic range $(\sim 4 \mu \mathrm{m})$ of the effective radius, forcing the correlation coefficient to always be low. In other words, retrievals can be accurate (i.e., comparable to input uncertainties) but weakly correlate to the truth. 
Acknowledgements. This research was supported by the Office of Science (BER, US Department of Energy, Interagency Agreement No. DE-SC0006001) as part of the ARM program. The authors thank L. Gregory, L. Ma and R. Wagener for establishing and maintaining the ARM cloud-mode site used in this investigation. We also thank the AERONET team for calibrating and maintaining instrumentation and processing these data. Thank to M. Ambaum, G. Feingold, G. Petty, S. Platnick, S. Xie, C. Zhao, and Z. Zhang for stimulating discussions.

Edited by: J. Quaas

\section{References}

Albrecht, B. A.: Aerosols, cloud microphysics, and fractional cloudiness, Science, 245, 1227-1230, 1989.

Cahalan, R. F., Oreopoulos , L., Marshak, A., Evans, K. F., Davis, A. B., Pincus, R., Yetzer, K., Mayer, B., Davies, R., Ackerman, T., Barker, H., Clothiaux , E., Ellingson, R., Garay, M., Kassianov, E., Kinne, S., Macke, A., OHirok, W., Partain, P., Prigarin, S., Rublev, A., Stephens, G., Szczap, F., Takara, E., Várnai, T., Wen, G., and Zhuravleva T.: The International Intercomparison of 3D Radiation Codes (I3RC): Bringing together the most advanced radiative transfer tools for cloudy atmospheres, Bull. Amer. Meteor. Soc., 86, 1275-1293, 2005.

Chang, F. L. and Li, Z.: Estimating the vertical variation of cloud droplet effective radius using multispectral near-infrared satellite measurements, J. Geophys. Res., 107, D154257, doi:10.1029/2001JD000766, 2002.

Chiu, J. C., Huang, C.-H., Marshak, A., Slutsker, I., Giles, D. M., Holben, B. N., Knyazikhin, Y., and Wiscombe, W. J.: Cloud optical depth retrievals from the Aerosol Robotic Network (AERONET) cloud mode observations, J. Geophys. Res., 115, D14202, doi:10.1029/2009JD013121, 2010.

Crewell, S. and Löhnert, U.: Accuracy of cloud liquid water path from ground-based microwave radiometer. 2. Sensor accuracy and syn- ergy, Radio Sci., 38, 8042, doi:10.1029/2002RS002634, 2003.

Dong, X. and Mace, G. G.: Profiles of low-level stratus cloud microphysics deduced from ground-based measurements, J. Atmos. Oceanic Technol., 20, 42-53, 2003.

Dong, X., Ackerman, T. P., and Clothiaux, E. E.: Parameterizations of the microphysical and shortwave radiative properties of boundary layer stratus from ground-based measurements, J. Geophys. Res., 103, 31681-31693, 1998.

Eck, T. F., Holben, B. N., Reid, J. S., Sinyuk, A., Dubovik, O., Smirnov, A., Giles, D., O’Neil, N. T., Tsay, S. C., Ji, Q., Mandoos, A., Khan, M. R., Reid, E. A., Schafer, J. S., Sorokine, M., Newcomb, W., and Slutsker, I.: Spatial and temporal variability of column-integrated aerosol optical properties in the southern Arabian Gulf and United Arab Emirates in summer, J. Geophys. Res., 113, D01204, doi:10.1029/2007JD008944, 2008.

Feingold, G., Furrer, R., Pilewskie, P., Remer, L. A., Min, Q. L., and Jonson, H.: Aerosol indirect effect studies at Southern Great Plains during the May 2003 Intensive Operations Period, J. Geophys. Res., 111, D05S14, doi:10.1029/2004JD005648, 2006.

Frisch, A. S., Fairall, C. W., and Snider, J. B.: Measurement of stratus cloud and drizzle parameters in ASTEX with K-band Doppler radar and microwave radiometer, J. Atmos. Sci., 52, 2788-2799, 1995.

Frisch, A. S., Feingold , G., Fairall, C. W., Uttal, T., and Snider, J. B.: On cloud radar and microwave radiometer measurements of stratus cloud liquid-water profiles, J. Geophys. Res., 103, 23,195-23,197, 1998.

Han, Q., Rossow, W. B., and Lacis, A. A.: Near-global survey of effective droplet radii in liquid water clouds using ISCCP data, J. Clim., 7, 465-497, 1994.

Heymsfield, A. J., Protat, A., Austin, R. T., Bouniol, D., Hogan, R. J., Delanoë, J., Okamoto, H., Sato, K., Van Zadelhoff, G.-J., Donovan, D. P., and Wang, Z.: Testing IWC retrieval methods using radar and ancillary measurements with in situ data, J. Appl. Meteorol. Climat., 47, 135-163, doi:10.1175/2007JAMC1606.1, 2008.

Hinkelman, L. M., Evans, K. F., Clothiaux, E. E., Ackerman, T. P., and Stackhouse, P. W.: The effect of cumulus cloud field anisotropy on domain-averaged solar fluxes and atmospheric heating rates, J. Atmos. Sci., 64, 3499-3520, 2007.

Hogan, R. J., Mittermaier, M. P., and Illingworth, A. J.: The retrieval of ice water content from radar reflectivity factor and temperature and its use in evaluating a mesoscale model, J. Appl. Meteorol., 45, 301-317, 2006.

Holben, B. N., Eck, T. F., Slutsker, I., Tanre, D., Buis, J. P., Setzer, A., Vermote, E., Reagan, J. A., Kaufman, Y. J., Nakajima, T., Lavenu, F., Jankowiak, I., and Smirnov, A.: AERONET - A federated instrument network and data archive for aerosol characterization, Remote Sens. Environ. 66, 1-16, 1998.

Illingworth, A. J., Hogan, R. J., O'Connor, E. J., Bouniol, D., Brooks, M. E., Delanoë, J., Donovan, D. P., Eastment, J. D., Gaussiat, N., Goddard, J. W. F., Haeffelin, M., Baltink, K. H., Krasnov, O. A., Pelon, J., Piriou, J.-M., Protat, A., Russchenberg, H. W. J., Seifert, A., Tompkins, A. M., van Zadelhoff, G.-J., Vinit, F., Willen, U., Wilson, D. R., and Wrenchet, C. L.: Cloudnet: Continuous evaluation of cloud profiles in seven operational models using ground-based observations, Bull. Am. Meteorol. Soc., 88, 883-898, 2007.

Kawamoto, K., Nakajima, T., and Nakajima, T. Y.: A global determination of cloud microphysics with AVHRR remote sensing, J. Clim., 14, 2054-2068, 2001.

Kikuchi, N., Nakajima, T., Kumagai, H., Kuroiwa, H., Kamei, A., Nakamura, R., and Nakajima, T. Y.: Cloud optical thickness and effective particle radius derived from transmitted solar radiation measurements: Comparison with cloud radar observations, J. Geophys. Res., 111, D07205, doi:10.1029/2005JD006363, 2006.

Kim, B.-G., Schwartz, S. E., Miller, M. A., and Min Q.: Effective radius of cloud droplets by ground-based remote sensing: Relationship to aerosol, J. Geophys. Res., 108, 4740, doi:10.1029/2003JD003721, 2003.

Kubar, T. L., Hartmann, D.-L., and Wood, R.: Understanding the importance of microphysics and macrophysics for warm rain in marine low clouds. Part I: Satellite observations, J. Atmos. Sci., 66, 2953-2972, doi:10.1175/2009JAS3071.1, 2009.

Liao, L. and Sassen, K.: Investigation of relationships between Kaband radar reflectivity and ice and liquid water contents, Atmos. Res., 34, 231-248, 1994.

Mace, G. G., Benson, S., Sonntag, K. L., Kato, S., Min, Q., Minnis, P., Twohy, C. H., Poellot, M., Dong, X., Long, C., Zhang, Q., and Doelling, D. R.: Cloud radiative forcing at the 
atmospheric radiation measurement program climate research facility: 1. Technique, validation, and comparison to satellitederived diagnostic quantities, J. Geophys. Res., 111, D11S90, doi:10.1029/2005JD005921, 2006.

Mace, G. G., Zhang, Q. Q., Vaughan, M., Marchand, R., Stephens, G., Trepte, C., and Winker D.: A description of hydrometeor layer occurrence statistics derived from the first year of merged Cloudsat and CALIPSO data, J. Geophys. Res., 114, D00A26, doi:10.1029/2007JD009755, 2009.

Marchand, R., Ackerman, T., Westwater, E. R., Clough, S. A., Cady- Pereira, K., and Liljegren, J. C.: An assessment of microwave absorp- tion models and retrievals of cloud liquid water using clear-sky data, J. Geophys. Res., 108, 4773, doi:10.1029/2003JD003843, 2003.

Marshak, A., Davis, A., Wiscombe, W., and Cahalan, R. F.: Radiative smoothing in fractal clouds, J. Geophys. Res., 100, 2624726261, 1995.

McBride, P. J., Schmidt, K. S., Pilewskie, P., Kittelman, A. S., and Wolfe, D. E.: A spectral method for retrieving cloud optical thickness and effective radius from surface-based transmittance measurements, Atmos. Chem. Phys., 11, 7235-7252, doi:10.5194/acp-11-7235-2011, 2011.

McComiskey, A., Feingold, G., Frisch, A. S., Turner, D. D., Miller, M. A., Chiu, J. C., Min, Q., and Ogren, J. A.: An assessment of aerosol-cloud interactions in marine stratus clouds based on surface remote sensing, J. Geophys. Res., 114, D09203, doi:10.1029/2008JD011006, 2009.

Min, Q.-L. and Harrison, L. C.: Cloud properties derived from surface MFRSR measurements and comparison with GOES results at the ARM SGP site, Geophys. Res. Lett., 23, 1641-1644, 1996a.

Min, Q.-L. and Harrison, L. C.: An adjoint formulation of the radiative transfer method, J. Geophys. Res., 101, 1635-1640, 1996b.

Min, Q.-L., Duan, M., and Marchand, R.: Validation of surface retrieved cloud optical properties with in situ measurements at the Atmospheric Radiation Measurement Program (ARM) South Great Plains site, J. Geophys. Res., 108, 4547, doi:10.1029/2003JD003385, 2003.

Minnis, P., Sun-Mack, S., Young, D. F., Heck, P. W., Garber, D. P., Chen, Y., Spangenberg, D. A, Arduini, R. F., Trepte, Q. Z., Smith, W. L., Ayers, J. K., Gibson, S. C., Miller, W. F., Hong, G., Chakrapani, V., Takano, Y., Liou, K. N., Xie, Y., Yang, P.: CERES Edition-2 Cloud Property Retrievals Using TRMM VIRS and Terra and Aqua MODIS Data Part I: Algorithms, IEEE T. Geosci. Remote, 49, 4374-4400, doi:10.1109/TGRS.2011.2144601, 2011.

Moeng, C. H., Cotton W. R., Bretherton, C., Chlond, A., Khairoutdinov, M., Krueger, S., Lewellen, W. S., MacVean, M. K., Pasquler, J. R. M., Rand, H. A., Siebesma, A. P., Stevens, B., and Sykes, R. I.: Simulation of a stratocumulus-topped planetary boundary layer: intercomparison among different numerical codes, Bull. Amer. Meteor. Soc., 77, 261-278, 1996.

Moody, E. G., King, M. D., Platnick, S., Schaaf, C. B., and Gao, F.: Spatially complete global spectral surface albedos: Value-added data sets derived from Terra MODIS land products, IEEE Trans. Geosci. Remote Sens., 43, 144-158, 2005.

Moody, E. G., King, M. D., Schaaf, C. B., Hall, D. K., and Platnick, S.: Northern Hemisphere five-year average (2000-2004) spectral albedos of surfaces in the presence of snow: Statistics computed from Terra MODIS land products, Remote Sens. Environ., 111, 337-345, 2007.

Nakajima, T. and King, M. D.: Determination of the optical thickness and effective particle radius of clouds from reflected solar radiation measurements, I: Theory, J. Atmos. Sci., 47, 18781893, 1990.

Nakajima, T., King, M. D., Spinhirne, J. D., and Radke, L. F.: Determination of the optical thickness and effective particle radius of clouds from reflected solar radiation measurements. Part II: Marine stratocumulus observations, J. Atmos. Sci., 48, 728-751, 1991.

Painemal, D. and Zuidema, P.: Assessment of MODIS cloud effective radius and optical thickness retrievals over the Southeast $\mathrm{Pa}-$ cific with VOCALS-REx in situ measurements, J. Geophys. Res., 116, D24206, doi:10.1029/ 2011JD016155, 2011.

Pandithurai, G., Takamura, T., Yamaguchi, J., Miyagi, K., Takano, T., Ishizaka, Y., Dipu, S., and Shimizu, A.: Aerosol effect on cloud droplet size as monitored from surface-based remote sensing over East China Sea region, Geophys. Res. Lett., 36, L13805, doi:10.1029/ 2009GL038451, 2009.

Platnick, S.: Vertical photon transport in cloud remote sensing problems, J. Geophys. Res., 105, 22919-22935, 2000.

Platnick, S. and Valero, F. P. J.: A validation of a satellite cloud retrieval during ASTEX, J. Atmos. Sci., 52, 2985-3001, doi:10.1175/1520-0469(1995)052<2985:AVOASC > 2.0.CO;2, 1995.

Platnick, S., King, M. D., Ackerman, S. A., Menzel, W. P., Baum, B. A., Riédi, J. C., and Frey, R. A.: The MODIS cloud products: Algorithms and examples from Terra, IEEE T. Geosci. Remote, 41, 459-473, doi:10.1109/TGRS.2002.808301, 2003.

Rawlins, F. and Foot, J. S.: Remotely Sensed Measurements of Stratocumulus Properties during FIRE Using the C130 Aircraft Multi-channel Radiometer, J. Atmos. Sci., 47, 2488-2504, 1990.

Roebeling, R. A., Feijt, A. J., and Stammes, P.: Cloud property retrievals for climate monitoring: Implications of differences between Spinning Enhanced Visible and Infrared Imager (SEVIRI) on METEOSAT-8 and Advanced Very High Resolution Radiometer (AVHRR) on NOAA-17, J. Geophys. Res., 111, D20210, doi:10.1029/2005JD006990, 2006.

Schaaf, C. B., Gao, F., Strahler, A. H., Lucht, W., Li, X .W., Tsang, T., Strugnell, N, C., Zhang, X. Y., Jin, Y. F., Muller, J. P., Lewis, P., Barnsley, M., Hobson, P., Disney, M., Rober ts, G., Dunderdale, M., Doll, C., d'Entremont, R. P., Hu, B. X., Liang, S. L., Privette, J. L., and Roy, D.: First operational BRDF, albedo nadir reflectance products from MODIS, Remote Sens. Environ., 83, 135-148, 2002.

Schofield, R., Daniel, J. S., Portmann, R. W., Miller, H. L., Solomon, S., Eubank, C. S., Melamed, M. L., Langford, A. O., Shupe, M. D., and Turner, D. D.: Retrieval of effective radius and liquid water path from ground-based instruments: A case study at Barrow, Alaska, J. Geophys. Res., 112, D21203, doi:10.1029/2007JD008737, 2007.

Slingo, A.: Sensitivity of the Earth's radiation budget to changes in low clouds, Nature, 343, 49-51, 1990.

Stamnes, K., Tsay, S.-C., Wiscombe, W. J., and Jayaweera, K.: Numerically stable algorithm for discrete-ordinate-method radiative transfer in multiple scattering and emitting layered media, Appl. Opt., 27, 2502-2512, 1988. 
Stokes, G. M. and Schwartz, S. E.: The Atmospheric Radiation Measurement (ARM) Program: Programmatic background and design of the cloud and radiation test bed, Bull. Am. Meteorol. Soc., 75, 1201-1221, 1994.

Stephens, G. L.: Radiation profiles in extended water clouds I: Theory, J. Atmos. Sci., 35, 2111-2122, doi:10.1175/15200469(1978)035<2111:RPIEWC>2.0.CO;2, 1978.

Stephens, G. L.: Radiative effects of clouds and water vapor, in Global Energy and Water Cycle, edited by: Browning, K. A. and Gurney, R. J., 71-90, Cambridge Univ. Press, New York, 1999.

Stephens, G. L.: Cloud feedbacks in the climate system: A critical review, J. Clim., 18, 237-273, 2005.

Tukey, J. W.: Exploratory Data Analysis, 688 pp., Addison-Wesley, Reading, Mass., 1977.

Turner, D. D.: Improved ground-based liquid water path retrievals using a combined infrared and microwave approach, J. Geophys. Res., 112, D15204, doi:10.1029/2007JD008530, 2007.

Turner, D. D., Clough, S. A., Liljegren, J. C., Clothiaux, E. E., Cady-Pereira, K., and Gaustad, K. L.: Retrieving liquid water path and precipitable water vapor from Atmospheric Radiation Measurement (ARM) microwave radiometers, IEEE Trans. Geosci. Remote Sens., 45, 3680-3690, doi:10.1109/TGRS.2007.903703, 2007.

Wang, Z. and Sassen, K.: Cirrus cloud microphysical property retrieval using lidar and radar measurements. Part I: Algorithm description and comparison with in situ data, J. Appl. Meteorol., 41, 218-229, 2002.
Wang, Z., Sassen, K., Whiteman, D. N., and Demoz, B. B.: Studying altocumulus with ice virga using ground-based active and passive remote sensors, J. Appl. Meteor., 43, 449-460, 2004.

Wielicki, B. A., Harrison, E. F., Cess, R. D., King, M. D., and Randall, D. A.: Mission to Planet Earth: Role of clouds and radiation in climate, Bull. Amer. Meteor. Soc., 76, 2125-2153, 1995.

Wood, R.: Parametrization of the effect of drizzle upon the droplet effective radius in stratocumulus clouds, Quart. J. Roy. Meteor. Soc., 126, 3309-3324, 2000.

Wood, R. and Harmann, D. L.: Spatial variability of liquid water path in marine low cloud: The importance of mesoscale cellular convection, J. Climate, 19, 1748-1764, 2006.

Zhang, Z. and Platnick, S.: An assessment of differences between cloud effective particle radius retrievals for marine water clouds from three MODIS spectral bands, J. Geophys. Res, 116, D20215, doi:10.1029/2011JD016216, 2011.

Zhao C., Xie, S., Klein, S. A., Protat, A., Shupe, M. D., McFarlane, S. A. Comstock, J. M., Delanoë, J., Deng, M., Dunn, M., Hogan, R. J., Huang, D., Jensen, M. P., Mace, G. G., McCoy, R, O'Connor, E. J., Turner, D. D., and Wang, Z.: Toward understanding of differences in current cloud retrievals of ARM ground-based measurements, J. Geophys. Res., 117, D10206, doi:10.1029/2011JD016792, 2012. 